Qhe Ontogeny and Phylogeny of the Sternum

FRANK BLAIR HANSON

Zoological Laboratory of Washington University, St. Louis, Missouri

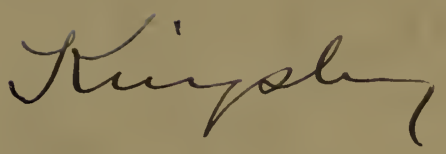

Reprinted from The American Journal of ANatomy, Vol. 26, No. 1, September, 1919

THE LIBRARY

OF THE 



\section{THE ONTOGENY AND PHYLOGENY OF THE STERNUM}

\section{FRANK BLAIR HANSON.}

Zoological Laboratory of Washington University, St. Louis, Missouri

TWELVE PLATES (FORTY-NINE FIGURES)

\section{CONTENTS}

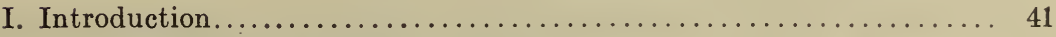

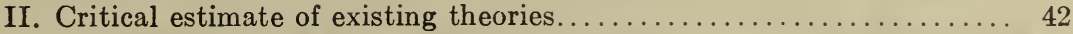

1. Ruge's theory of costal origin...................... 42

2. Paterson's coracoidal theory ...................... 43

3. Work of Parker and Howes....................... 45

4. Whitehead and Waddell's 'in situ' theory ................ 47

5. Work of Rathke, Kravetz, Mueller, etc................ 52

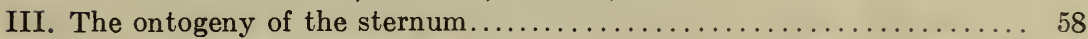

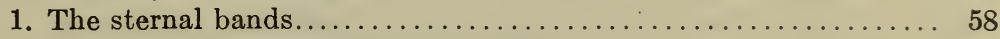

2. The anterior median sternal rudiment................. 60

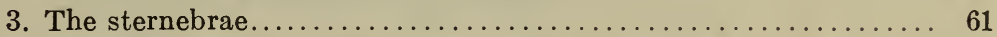

4. Stages in the ontogeny of the mammalian sternum.......... 63

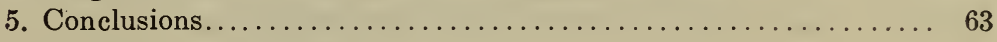

IV. The phylogeny of the sternum $\ldots \ldots \ldots \ldots \ldots \ldots \ldots \ldots \ldots \ldots \ldots \ldots \ldots \ldots$

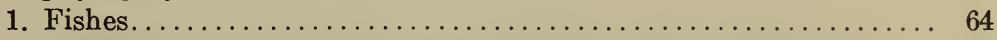

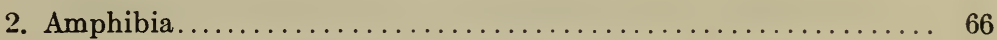

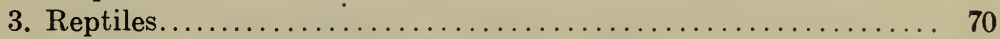

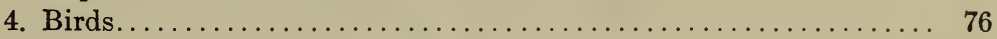

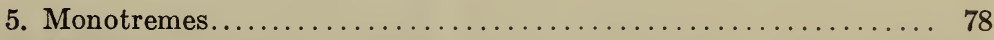

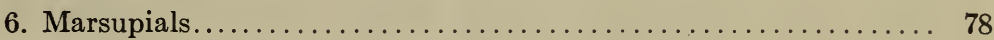

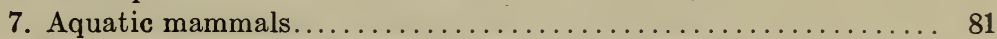

8. The adult human sternum $\ldots \ldots \ldots \ldots \ldots \ldots \ldots \ldots \ldots \ldots \ldots$

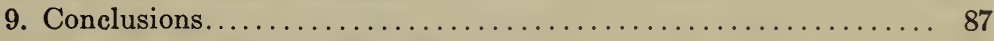

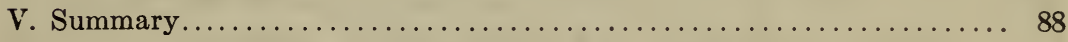

\section{INTRODUCTION}

The shoulder-girdle complex presents some of the most fascinating and difficult problems of vertebrate morphology. In all the lower vertebrates the sternum, because of its intimate relation to the coracoids, enters into and constitutes one of these problems. Its origin, development, and homologies have been 
the subject of numerous contributions for a century past, yet to-day there is no general agreement upon many of the points involved.

For several years the writer has been studying the shouldergirdle region in the vertebrates. This included also a restudy of the origin of the sternum, the results of which are embodied in this paper. The fact that my conclusions are at variance with the usually accepted theory of sternum origin only adds to the interest of the undertaking. If this paper settles the points at issue or stimulates further investigation upon the part of others, it will in either case not have been in vain.

One of the recognized deficiences of much of the previous work is that general and far-reaching conclusions have been deduced from the study of only one or two forms, and these most often the more highly specialized ones. The author has attempted herein to bring together corroborating lines of evidence from both ontogeny and phylogeny, believing that a theory of sternal origin only so demonstrated can command consideration.

I desire to express my deep appreciation for the constructive criticisms and helpful suggestions given by Prof. J. Sterling Kingsley during the course of this investigation.

\section{CRITICAL ESTIMATE OF EXISTING THEORIES}

\section{Ruge's theory of costal origin}

Ruge ('80) was the first investigator to work up and present a well-developed and illustrated paper containing a theory of the origin of the sternum. His fifty pages of text and twenty-two figures gave his theory a commanding place in the literature. Most books on human and comparative anatomy, until the present day, copy his figures and accept his view that the sternum arises as a product of the ventral costal cartilages. As an example of this, Keibel and Mall in their two-volume Embryology give the following statement concerning the origin of the sternum: "The cartilage of the sternum arises mainly from the cartilage of the ribs, from which it is secondarily separated by the formation of the costosternal joints." So completely has Ruge's 
work dominated the field that even in the latest editions of Human Anatomy texts his work is alone mentioned, or at most, a footnote is added to the effect that this view has of late been questioned by some.

However, there are at least two later views as to the origin of the sternum. Paterson ('00, '02, '04), on the one hand, and Whitehead and Waddell ('11), on the other, have propounded theories which are at once contradictory of Ruge's view and also antagonistic to each other. Thus there are at the present time three distinct and opposing theories concerning the origin of the sternum, and it was with a view to clearing up this confusion and also to give the prominence deserved to this later work that the present investigation was undertaken. For while a study of the papers representing these theories may not convince one of the validity of any one of them as opposed to the others, the latter two mentioned do point out very clearly that there are data which Ruge did not consider; and further, that our commonly accepted view concerning the origin of the sternum, held for nearly forty years, must be greatly modified and possibly cast aside altogether.

\section{Paterson's coracoidal theory}

Professor Paterson in a series of papers ('00, '02, '04) was the first to attempt to overthrow Ruge's theory of the origin of the sternum from the ventral ends of the ribs. His observations were made upon the rat, rabbit, and man. He describes a single median rudiment which is directly continuous with the mass of cells destined to form the shoulder-girdle. From this median mass two strands of cells grow caudally to form the sternal bands. Whitehead and Waddell ('11) say, "thus in the final analysis, according to Paterson's view, the sternum is derived from the shoulder-girdle." This seems an unwarranted statement. It would be as correct to say that, according to Paterson, the shoulder-girdle is derived from the sternum as to say, as do Whitehead and Waddell, that Paterson makes the sternum to be a derivative of the shoulder-girdle. What Paterson does succinctly say is, "that the presternum and shoulder-girdle are 
originally derived from the same (italies mine) element; a primitive band of cellular tissue which crosses the midline." Paterson has no interest in deriving the sternum from the shoulder-girdle or vice versa; his contention being, first, that the sternum is not a product of the costal cartilages, and, second, that it is yielded from a common, continuous, mesenchymatous element which gives rise to the shoulder-girdles and the sternum.

Paterson ('02) compares this continuous cellular element in the rat to the girdle in the elasmobranchs. He exhibited before the British Medical Association his sections of rat embryos side by side with embryos of Acanthias vulgaris to demonstrate that "essentially the same method of development occurs in the dogfish and in the rodent. But a marked difference is produced in the process of development. Instead of a jointed and highly differentiated structure such as is characteristic of mammals, a simple continuous bar of cartilage is formed, across the middle line and below the heart, which gives rise laterally to the primitive shoulder-girdle."

Paterson ('00) also points out, and gives several figures in substantiation, that the parts of the sternum opposite the costal attachments remain longest in a cellular condition. His point being, of course, that if the sternum were ossified from the ribs, these regions should ossify first, and not last as is actually the case.

This comparison of the girdles in the shark and rat embryos is very suggestive. Many other structures of present-day mammals may be traced directly back to homologous structures in the elasmobranchs, and since in the cartilaginous girdle of the shark we have all the necessary material and in proper position for differentiation into scapulae, coracoids, and sternum, we might even upon a priori grounds expect to find in the higher groups of vertebrates an embryonic stage in which the rudiment of the girdles and sternum might be represented by such a "continuous bar . . . . reaching across the middle line" as Paterson found in the rat. 


\section{Work of Parker and Howes}

Parker ('91) claims to have found a sternum in the shark Notidanus indicus. A small blunt process is set in between the two cartilages which unite later to form the girdle. This structure was earlier described in the same shark by Haswell ('84) who says "the intercepted cartilage is temptingly like a presternal, but the absence of such an element in the skeleton of any group nearer than the Amphibia seems to preclude this explanation." Parker's ('91) figures 1 and 2 would indicate that this was a presternum, and that Haswell was more nearly correct in.his observation than in his deduction therefrom. Had Paterson used Hexanchus rather than Acanthias, he might have found an even more striking resemblance of stages between the rat and shark than he did.

By the courtesy of the officials of the U. S. National Museum, I was permitted to examine their type specimen of Hexanchus. The body wall had been laid open along the ventral side to allow the preserving fluid to bathe the viscera. By means of a short anterior and two lateral incisions I was enabled to lay bare the median ventral portion of the pectoral girdle without otherwise disturbing the value of the specimen as a type. The girdle (fig. 1) was exactly as described by Haswell ('84) and Parker ('91). The median cartilage in a young specimen was distinctly marked off from the coracoids and in general appearance was not unlike the fetal girdle of the marsupial (fig. 35). Later I dissected two specimens of Acanthias that measured 4 inches and 7 inches, respectively, in order to confirm Paterson's statement of its likeness to the early embryonic girdle of the rat. In both these specimens the girdle was approximately the same as in the adult. Figure 2 shows the girdle of the 7 -inch specimen, and if compared to the marsupial girdle (fig. 35) and the mouse girdle (fig. 5), the morphological relations are apparent. In these early stages of the marsupial and mouse no suture has as yet appeared between coracoids and presternum, giving the resulting shark-like girdle, complete across the midventral line. 
Parker ('91), accepting in common with others the validity of Ruge's theory of a costal sternum in reptiles, birds, and mammals, but being unable to relate a sternum of such derivation with the sterna of the Ichthyopsida, suggested that there must be two distinct types of sterna: 1) a costal sternum, characteristic of the Amniota, and 2) a coracoidal or clavicular sternum, characteristic of the Ichthyopsida.

This classification of the sternum was adopted by Howes ('91) who says, "the distinction indicated by the two terms 'costal sternum' and 'coracoidal sternum' is but the expression of a fundamental morphological difference between the two structures." Howes slightly altered the terminology of Parker. $\mathrm{He}$ would distinguish between a 'coracoidal archisternum' of the Ichthyopsida and a 'haemocoracoidal neosternum' of the Amniota. This latter term was based upon his idea that the "interclavicle may be, throughout, the vanishing vestige of the coracoidal sternum of the Ichthyopsida." The acceptance by Parker ('91) and by Howes ('91) of this division of two morphologically different sterna in the group of the vertebrates indicates how completely Ruge's theory dominated their thoughts, and the thought and teaching of that day concerning the origin of the sternum. If, however, the conclusions of later workers regarding Ruge's theory prove valid, and all the facts at the present time seem to substantiate their validity as we shall later see, it is no longer necessary to divide the sterna of the various classes of vertebrates into coracoidal and costal, for no sternum is costal in origin, the union of ribs and sternum being but a late and secondary stage in development. This is obviously an important item, if proved, for it enables us to homologize all vertebrate sterna. Heretofore it has been impossible to homologize the sterna of the Ichthyopsida and the Amniotes because of their supposed dual origin. One of the objects of the present paper is to determine this matter of a single or dual origin for the sternum and the solution of its homology throughout the vertebrates. 


\section{Whitehead and Waddell's 'in situ' theory}

In 1911 Whitehead and Waddell undertook to settle the whole vexed question by a reexamination of all the evidence and by a study of younger stages than had hitherto been used. Their work was based on observations made upon three forms: the pig, cat, and man. These studies, however, instead of settling the dispute between the theories of Ruge and Paterson, led the authors to reject both of them and to propound an entirely new one. So, as a result of this latest paper, there are at the present time three, instead of two, rival theories of sternal origin. For neither of these two latter theories had been able of its own weight effectually to settle the points in question; Ruge's theory of costal origin still maintains its hold upon the minds of most morphologists; but nevertheless, new evidence produced by later work throws very strong doubt upon the conclusions of Ruge.

Ruge apparently had no stage prior to that in which the sternal bands were united with the costal cartilages; but it must be admitted, that his conclusions, based upon the material that passed through his hands, are clearly valid for the stages describedin fact, the only ones that could possibly be deduced therefrom. It is probably this fact that gave Ruge's theory its persistence through the years. The later workers, however, have had as their goal stages much earlier than Ruge's, and, while they have succeeded in finding them, are still very far apart in the interpretation thereof.

As Whitehead and Waddell's paper is of considerable importance and has never been reviewed, a brief summary of its contents and conclusions is necessary here.

They studied first the pig, because the absence of clavicles in this form tends to simplify matters at the cranial end of the sternal rudiment; next the cat, for here the clavicle is a rudimentary bone and does not articulate with the sternum, and finally the human embryo, where the clavicle reaches its fullest development.

These authors began with pigs of $24 \mathrm{~mm}$. and worked through successively smaller stages, until the sternal rudiment was very 
feeble, while in specimens smaller than $15 \mathrm{~mm}$. no rudiment could with certainty be detected.

In a pig $24 \mathrm{~mm}$. long, to follow the description of Whitehead and Waddell, the sternal rudiment is an aggregation of mesenchymal cells lying transverse to the median plane of the body. In cross-section it is triangular, with the apex directed ventrally, and each lateral angle of the base connected with the corresponding first rib, there being a perfect and direct continuity of tissue between the rudiment of the first rib and that of the sternum. Proceeding backward in the series of sections two bands of mesenchymal cells separate from the mass and extend as far back as the level of the seventh rib, all seven ribs being connected with and shading off into the sternal bands without any definite demarkation. This is the stage in which Kravetz ('05) found that the first ribs did not reach the sternal rudiment, and the junction of the other six ribs was too feeble to have any morphological significance. Whitehead and Waddell think this is not a tenable conclusion in light of the intermediate position occupied by this specimen, i.e., between older stages in which no doubt of the absolute continuity of ribs and sternum exists, and younger stages in which they seek for new facts concerning the earliest relation between these two structures.

In a $20-\mathrm{mm}$. pig the pericardial cavity extends into the neck, the ventral ends of the ribs are wide apart, and, in the region anterior to the level of the first rib, the sternal rudiment is present and is composed of three parts: the two sternal bands and a plate of more diffused mesenchymal cells connecting the two across the middle line. This stage presents two facts worthy of note: the sternal bands are well defined separate structures at a level considerably anterior to that of the first rib, and, further, in this anterior region the two sternal bands are connected by a median aggregate of cellular tissue. Posteriorly, in the region of the ribs, there is the same continuity between costal extremity and sternal band as in the $24-\mathrm{mm}$. stage.

Just as the older stage of Whitehead and Waddell (24-mm. pig) corresponded to the youngest studied by Kravetz, so does this $20-\mathrm{mm}$. stage in the pig correspond essentially to the youngest 
stage in man found by Mueller ('06), yet the interpretations of these stages by the three authors are totally at variance.

The next stage was a $22-\mathrm{mm}$. pig, longer than the preceding by $2 \mathrm{~mm}$., but distinctly a younger stage in so far as development of these parts was concerned. The sternal bands and connecting bridge of mesenchymal cells are still anterior to the first ribs; the pericardial cavity reaches far into the neck and separates the sternal band and first rib of each side. Passing caudally in the series of sections, the first rib falls just short of reaching the sternal band; the extremity of the second rib approaches more nearly to the sternal band, and the remaining five present the same continuity as before.

In the next younger stage, the $18-\mathrm{mm}$. pig, the heart is far forward in the neck, with the consequent wide separation of the sternal bands in this region; the median connecting portion is now absent; the remaining parts of the sternal bands were traced from a point $150 \mu$ anterior to the level of the first ribs back to the level of the ventral extremity of the seventh; the first two pairs of ribs do not reach the sternal bands, but the other five are firmly fused with it.

The earliest stages in which any sternal rudiment could be detected were in 15- and 16-mm. pigs. The bands are not very clearly defined and stop at the level of the third and fourth ribs, respectively; again the first and second ribs fail to reach the sternal bands, and it is the opinion of the authors that, "judging from the behavior of the ventral extremities of the first and second ribs in somewhat older stages, we think it probable that a stage exists in which no rib is connected directly with the sternal bands, but we were unable to detect such a stage."

The cat embryos studied by Whitehead and Waddell (from the Princeton Embryological Collection) ranged in size from $25 \mathrm{~mm}$. to $10 \mathrm{~mm}$. From the description given, they are essentially the same as the several corresponding stages of the pig. In the 12-mm. cat the first three ribs clearly did not reach the sternal bands, the fourth was uncertain, while the three posterior pairs made the connection. Since, from the account given, the early stages in the pig and cat are practically identical, nothing further need be said of the sternum in the cat. 
Several human embryos from the Johns Hopkins Embryological Collection, ranging in size from 17.2 to $10.5 \mathrm{~mm}$. are described in the paper now under review. The $13-\mathrm{mm}$. human embryo corresponds essentially to the $18-\mathrm{mm}$. pig and $13-\mathrm{mm}$. cat. The pericardial cavity extends far forward; the sternal bands are traceable to the level of the ventral extremities of the fifth ribs; the ventral tips of the ribs are non-cartilaginous, and any possible continuity between them and the sternal bands is much too slight to suggest that the latter is a derivative of the former; neither median sternal rudiment nor clavicles were detected, though this was probably due to the loss of an entire slide of sections from the very region in which one would expect such a structure to occur, if present.

In a $10.5-\mathrm{mm}$. human embryo, the sternal bands reach posteriorly only as far as the fourth rib; and although the cells composing the bands are not sharply differentiated from the surrounding tissue, they are still recognizable and "it is evident that they are not continuous with the tips of the ribs, but are connected with them only by loose mesenchymal cells."

In these stages which are far earlier than any Ruge describes, there is a history quite different from that which later stages had led us to expect. In the first place, there was no indication of segmentation in the sternal bands, which might be expected were these bands due to proliferated cells from the tips of the costal cartilages, and, second, in the pig the first two ribs in the earliest stages studied did not reach the sternal bands at all; three did not do so in the cat, while in the $10.5-\mathrm{mm}$. human embryo none of the ribs reached the band.

These results also contradict the statement of Paterson that the median rudiment is a part of the scapular arch, and that the sternal bands are derivatives of the single median blastema. Whitehead and Waddell do not mention the condition or extent of the girdles in any of the forms studied by them, merely stating that at no point was there any connection discernible between sternum and girdles; and that in every case "the appearance of the paired portion of the rudiment, the sternal bands, antedates that of the median portion." 
Since the observations of Whitehead and Waddell accord with neither those of Ruge nor of Paterson, the formulation of a new theory of sternal origin was necessary.

Their discovery of the single median rudiment would not allow of Ruge's conclusion, for he thought the sternum a product of the costal extremities; neither would they square with Paterson's view, for he derived the sternal bands from the median rudiment; and further, it was apparently not a product of the sternal ends of the clavicles. So recourse was had to either of two other theories, each possible so far as their observations go: "first, it may be formed 'in situ,' or, second, it may be derived from the anterior ends of the sternal bands by each of them sending a prolongation medialward to join its fellow in the median plane. The fact that we never found this rudiment in a paired condition, but always as a single band of cells uniting the anterior ends of the sternal bands leads us to believe that the first interpretation is the more probable."

Thus Whitehead and Waddell say there are two possibilities remaining for the formation of the anterior median rudiment, either that it arises 'in situ' or as a derivative of the sternal bands. They overlooked another possibility, its derivation from and relation to the shoulder-girdle. This may not have been an unnatural error in view of the fact that they studied chiefly the pig where the clavicle and that associated coracoidal mesenchymatous material of the early embryo is lacking. Their view-point was derived from the developmental stages in one or two mammals only, and they paid little attention to the comparative anatomical and the phylogenetic side.

This median rudiment is considered by Whitehead and Waddell to be the homotype of the presternum of monotremes, but no reasons or arguments for such a belief are set forth. This conclusion, however, is clearly invalid, for it is impossible to reconcile the theory of 'in situ' for this anterior rudiment with their statement that it finds its homologue in the presternum of lower forms or the so-called prosternum of monotremes. If these be homologous, then the presternum and prosternum also arise 'in situ,' and no morphologist believes that they do. 
The paired rudiments, or sternal bands, also arise very early, according to Whitehead and Waddell, 'in situ,' one on either side of the body and unattached in the earlier stages to the ventral extremities of the ribs. The paired rudiments antedate the appearance of the median rudiment.

While Whitehead and Waddell and Paterson are very far from being in accord as to the origin of the sternal rudiments, they agree in demonstrating that the attachment of ribs and sternum is a secondary fusion of parts, and that Ruge, while essentially correct in his description of the stages he had under observation, did not have the earlier stages and therefore was not in a position to frame a theory of sternal origin. Without stopping now to consider the relative merits of these two later theories, it must be pointed out that their united efforts in overthrowing the Ruge theory are of great value because of the hitherto widespread, almost universal acceptance of this view.

\section{Work of Kravetz, Rathke, Mueller, etc.}

Kravetz ('05) worked on the pig. His youngest stage (24 mm.) was also the oldest stage of Whitehead and Waddell. In the 24-mm. pig he found that the first ribs did not reach the sternal rudiment, and, from the conditions in a series of later stages, came to the conclusion that primarily there is no connection whatever between the sternal rudiment and the costal cartilages at their ventral ends.

Bruch ('52) describes the early stage of the sternum as two longitudinal rods, one on either side, which later unite with each other and with the ribs of their respective sides. He thus indirectly denies a costal origin, but fails to indicate just what his views were in this respect. It is highly probable that the question was never raised in his mind at that early date. Whitehead and Waddell add but little to the description of this early worker, except that they have a theory of 'in situ' origin for the structure in question.

Rathke ('48) has an early, but very important paper in connection with this discussion. His views are set forth in two short paragraphs which are quoted in full as follows: 
According to the researches I have made on the development of the sternum in mammals, birds, and batrachians, this bone (sternum) may be formed in a two-fold fashion. In mammals and birds it occurs under the form of two very slender, long rods (italics mine), divided into two lateral halves, and already at an early period consisting of cartilaginous tissue, each of which rods unites itself with the extremities of several ribs of its own side (italics mine) when these project themselves through a small part of the lateral wall of the body. The two halves, therefore, at first, lie at a considerable distance from each other. Gradually, however, these two rods are approximated to one another by the extension and development of the ribs, until, at length, they come into contact throughout their whole length, and ultimately coalesce, forming the sternum.

As regards the Batrachia, even in those which possess ribs, there is never at any time two rods which unite the ribs and coalesce with one another to form the sternum, but in some of these Amphibia there originates a single cartilaginous lamina; in others a row of two or three such laminae quite independent of the lateral rays of the vertebral column.

Rathke's account of the origin of the sternum in birds and mammals gives us a description of a stage far earlier than Ruge's youngest sternum. Ruge saw these 'rods, long and slender' only after they had been united with ribs, and therefrom made his deductions that they originated from ribs. Over thirty years before Ruge's paper, Rathke accurately described this very early stage, which had only been rediscovered in a few mammals very recently. Ruge mentions Rathke's work, but, strange to say, makes no reference to this earlier stage in his account.

This earlier account by Rathke is hidden in a discussion of the homologies of the Chelonian plastron, and has not been mentioned by any writer since Ruge. Its confirmation by Paterson, Whitehead and Waddell, as well as by my own observations, renders Ruge's theory of the sternum untenable.

However, accurate as this description of Rathke's is, we must not forget that he did not recognize its significance; in fact, it is introduced into a paragraph describing and maintaining that the sternum of the mammals is different in origin from that of batrachians, not realizing as we do to-day that in separating it completely in its genesis from the costal cartilages, he made unnecessary a dual theory of sternal origin. 
Charlotte Mueller ('06) worked out the development of the thorax in a series of human embryos. She modeled the entire thoracic framework, including vertebral column, ribs, and sternum. The series of models as pictured in her paper are fine examples of the possibilities in careful modeling of large and complicated structures. However, her youngest stage had the sternal bands, though remote from each other, firmly fused on either side with the costal cartilages, and, following Ruge, she describes the sternal bars as arising from the ribs. She makes little other contribution to the subject of sternal genesis, for her material, like Ruge's, was far too advanced for the early history of this bone.

It is at once apparent that the theory of Parker, Ruge, Mueller, etc., on the one hand, and those of Paterson, Whitehead and Waddell on the other are mutually exclusive. But it would seem that those of Paterson and Whitehead and Waddell have only an apparent incompatibility, and that at least in so far as their observations go, each was correct in reporting what he saw, but the fact that they worked on very different forms and interpreted their results in a widely different manner, leads to the belief that they were looking on opposite sides of the same shield, and that it is possible to reconcile the two.

The 'in situ' theory of Whitehead and Waddell is hardly to be taken seriously. So ancient a structure as the sternum, dating back to the Elasmobranchs, as we have seen, and found in every higher group of vertebrates, including at least one or two teleosts, and having an enormous and highly complex development in many of the groups, can scarcely be accounted for in this simple fashion. 'The 'in situ' theory took form from the material upon which its authors worked. The pig is the basis of their main conclusions and this form is peculiarly unsuited for this work, because of the degenerate character of the shoulder-girdle, which is lacking at once in both clavicle and coracoid process (the socalled subcoracoid now being thought to be an epiphysis). For a proper interpretation of the sternum and shoulder-girdle in the mammals those groups with well-developed clavicles, episternals, suprasternals, and other appurtenances of this 
region are the only ones which can be lined up with the lower groups of vertebrates. The rat was used by Paterson and the mouse is the basis of the present paper, and this would seem to be the ideal form; for the rodents, while highly specialized in some respects, are primitive in others, and are to be grouped with the Edentates and Insectivores somewhere near the monotreme stem. They are also small enough so that when sectioned, comparatively high powers of the microscope may be used, and it is possible to section all stages up to the ripe fetus.

Discarding, then, Whitehead and Waddell's theory of sternal origin, while retaining an appreciative memory for their valuable work in combating one of the remaining theories, we can reduce the great mass of papers and discussion on this subject to just two absolutely irreconcilable theories of sternal origin, which may for convenience in treatment be designated as Ruge's 'theory of costal origin,' and Paterson's 'theory of coracoidal origin.' All other workers, except Whitehead and Waddell, have supported one or other of these theories or modifications of them. ${ }^{1}$

${ }_{1}^{1}$ Through the courtesy of Doctor Kingsley, I have just received two papers on the sternum, one of which requires mention. This is by Albrecht: Sur les Copulae Intercostoidales et les Hemisternoides du Sacrum des Mammifers. Bruxelles, 1883. It contains a most curious modification of Ruge's theory of costal origin. Albrecht's idea is that the first and second ribs of each side at first are united by an arch of cartilage, giving, according to his schematic figures, a structure similar to a horseshoe magnet, the two arms of the magnet being the ribs, the arch connecting them the sternal band. Then by a union of the two sides in the midline, and the fusion of the consecutive pairs of such magnetshaped structures, a sternum is derived. This is ingenuous and is the only theory of costal origin which gives the sutures between the sternebrae their proper position, i.e., opposite the ends of the ribs, making the sternebrae intercostal as they actually are. However, the arguments used to overthrow Ruge's theory apply equally here. This theory does not account for the anterior and posterior extension of the sternal bands for a considerable distance beyond the region of ribs; it does not explain the appearance of the bands prior to their union with ribs; and fatal to Albrecht's hypothesis is the fact that the bars are continuous, unsegmented structures throughout their entire length from their earliest appearance in the mesenchyme, and never occur in short, semicircular segments connecting the ends of the ribs. Albrecht was evidently unable to find any stages in actual material in support of his theory, for his figures without exception are diagrammatic, and do not fit the observed facts of sternal development. 
To sum up, then, there are extant at the present time in the literature three opposing theories as to the origin of the sternum in the Mammalia. The oldest and most generally accepted of these is that proposed by Ruge in 1880, which in substance states that the sternum is a direct derivative of the ventral ends of the costal cartilages.

In 1900 and more fully in 1902 and 1904, Paterson was led to doubt the validity of Ruge's theory, claiming that there was an earlier history than that of which Ruge was aware. Paterson derived the presternum from the same element which gives rise to the shoulder-girdle, describing a continuous cellular element crossing the midline in the rat. He derived the sternal bands from this presternum as backward prolongations, which later and secondarily are fused with the ventral ends of the ribs.

Whitehead and Waddell ('11) agree with Paterson that Ruge did not have the earliest stages, and that his theory is therefore untenable, but they disagree with Paterson as to the interpretation of these early stages. They deny any connection or relation between sternum and shoulder-girdle, believing that both presternum and sternal bands arise 'in situ.'

This discussion of the literature is one of selected papers which supports one or other of the different theories of sternal origin and is fairly representative of the literature. However, only a few papers are mentioned in comparison with the voluminous literature extant. The author has collected a bibliography of about one hundred titles on the sternum, but has considered it necessary to treat only a few of the more prominent ones in this connection, with the assurance that those omitted contain nothing new or affect the situation as outlined here.

It has added greatly to the confusion existing between these opposing theories that most of the more important papers (Ruge's excepted) are very inadequately illustrated. Paterson ('02) does not give a single figure in this paper and his figures in the 1900 paper are small and inadequate. Important stages are described in the Whitehead and Waddell paper, but those upon which they base their chief conclusions are not supported by any figures. If we had clear-cut drawings of Paterson's continuous 
cellular element extending across the middle line, and could compare this with equally well-drawn stages from the material of Whitehead and Waddell, an unprejudiced worker, from a study of the figures, supplemented by his own observations, might bring the whole tangled mass into harmony. As it is, the present author has but little to start with except the verbal statements of the opposing theorists.

Table 1 gives at a glance the position of several of the leading workers in their attitude toward the problem.

TABLE 1

\begin{tabular}{|c|c|c|c|}
\hline & ORIGIN OF STERNUM & FORMS STUDIED & $\begin{array}{c}\text { HOMOLOGY } \\
\text { OF PRESTERNCM }\end{array}$ \\
\hline Ruge, G. ('80) & $\begin{array}{l}\text { Ventral ends of } \\
\text { ribs }\end{array}$ & Man & \\
\hline $\begin{array}{l}\text { Paterson ('00) } \\
\text { Paterson ('02) } \\
\text { Paterson ('04) }\end{array}$ & Shoulder girdle & $\begin{array}{l}\text { Rat, rabbit, man, } \\
\text { dogfish }\end{array}$ & $\begin{array}{l}\text { Middle part shark } \\
\text { girdle }\end{array}$ \\
\hline Kravetz ('95) & $\begin{array}{l}\text { Two longitudinal } \\
\text { bars }\end{array}$ & Pig & $\begin{array}{l}\text { No morphological } \\
\text { importance }\end{array}$ \\
\hline Muéller ('06) & $\begin{array}{l}\text { Ventral ends of } \\
\text { ribs }\end{array}$ & Man & Episternum \\
\hline Parker ('91) & $\begin{array}{l}\text { Coracoidal and } \\
\text { costal }\end{array}$ & $\underset{\text { teryx }}{\text { Hexanchus Ap- }}$ & $\begin{array}{l}\text { Omo-sternum in } \\
\text { shark; omo-ster- } \\
\text { num in am- } \\
\text { phibia }\end{array}$ \\
\hline $\begin{array}{l}\text { Whitehead-Wad- } \\
\text { dell ('11) }\end{array}$ & 'In situ' & Pig, cat, man & $\begin{array}{l}\text { Episternum; pro- } \\
\text { sternum }\end{array}$ \\
\hline Rathke ('48) & $\begin{array}{l}\text { Two longitudinal } \\
\text { bars }\end{array}$ & $\begin{array}{l}\text { Batrachia, chick, } \\
\text { pig }\end{array}$ & \\
\hline
\end{tabular}




\section{THE ONTOGENY OF THE STERNUM}

The earliest development of the sternum in a number of mammals has, been worked out by Paterson, Kravetz, Whitehead and Waddell, and myself. An attempt is made to compare the steps of development in ontogeny with those in the phylogeny of the sternum, or in other words to make a practical demonstration of Haeckel's recapitulation theory as applied to sternal development.

\section{The sternal bands}

One decisive result of this investigation has been to demonstrate the existence of the sternal bands as independent structures far earlier in development than Ruge and the older workers suspected. Hence a new theory of sternal origin was demanded, and as above indicated, this has taken two directions: Whitehead and Waddell do not relate the sternal rudiment genetically to any preexisting structure, while Paterson identified it with the coracoidal girdle of lower forms.

The conclusive evidence against Ruge's theory of costal origin led the author to examine the material of Paterson and Whitehead and Waddell, in an effort to confirm one or other of these workers or reject both, as the case might be. Paradoxically enough, I have been able to corroborate Paterson's account of the shark-like girdle, found by him in the rat, both in the mouse and human embryos; and in the identical slides ${ }^{2}$ of cat and human embryos used by Whitehead and Waddell have been equally able to confirm their observations. In pig embryos of 24-mm. length, Kravetz found that the first rib did not reach the sternal band, and the connections of the remaining six ribs were too feeble to have any morphological importance. Whitehead and Waddell studied a 24-mm. pig in which the first rib did just reach the sternal rudiment and the union of the other six ribs was marked. My 24-mm. stage agrees with that of Kravetz in that the first rib does not reach the band, and with Whitehead and Waddell's in that the connection of the other

' My sincere thanks are tendered Dr. C. W. F. McClure, of Princeton University, and Dr. George L. Streeter, of The Johns Hopkins University, for the loan of the series of cat and human embryo studied by Whitehead and Waddell. 
six is marked. No special significance attaches to these variations since individual differences in development as well as in measurements and amount of shrinkage gives form for considerable variation. However, in stages of the pig $22 \mathrm{~mm}$., 20 $\mathrm{mm}$., $18 \mathrm{~mm}$., and smaller, there is no doubt of the failure of several pairs of the anterior ribs to meet the sternal rudiment.

Figures 3 and 4 are of two cat embryos from the Princeton Embryological Collection. Camera-lucida drawings were made of the sternal bands and ventral ends of the ribs. These structures were then plotted upon millimeter-ruled paper, which gives a graphic reconstruction made to scale. Several wax models were also made from the early pig and mouse embryos. Figure 3 , of the $12-\mathrm{mm}$. cat embryo, shows clearly that in this stage the first three pairs of ribs do not extend to and unite with the sternal bands. It is also apparent that no anterior sternal rudiment or presternal rudiment is present at this age. It is undoubtedly true, as claimed by Whitehead and Waddell, that in the ontogeny of the mammalian sternum the two sternal bands antedate in appearance the median and anterior rudiment. However, in the phylogeny of the sternum, as will be shown further on, the presternum is the first to arise, and from this come the sternal bars. I am unable to account for this discrepancy by any observed facts, but think the history from phylogeny must take precedence over that from ontogeny; explaining the rise of the sternal bands in the mesenchyme of the mammal as the result of protoplasmic memory, which dates back to the early reptilian ancestor in which the presternum grew backward as two prolongations that became the mesosternum and the xiphisternum,

In human embryos from the F. P. Mall Collection studied by Whitehead and Waddell and myself, is found the best evidence of the complete separation of ribs and sternal bars in the early stages of development. In embryos $10.5 \mathrm{~mm}$. and $13 \mathrm{~mm}$. long none of the ribs reaches the sternum, the presternum has not yet appeared, and no clavicles are apparent. These stages, if graphically represented, would appear similar to figure 3 of the cat, except that all the ribs would be in the same relation to the sternum as are the first three in the stage of the cat figured. 


\section{The anterior median sternal rudiment}

In the mouse, rat, and human embryos occurs a stage in which a mesenchymatous girdle appears, in shape and relations comparable to the pectoral girdle of the shark. Figures 5 and 6 show this girdle in the mouse and human embryos. It is composed throughout of mesenchyme cells, and the structural development of each part may be followed in later stages. In the mouse girdle the two dorsally extending wings on either side are the rudiments of the scapulae; the medial and ventral extensions are the coracoids and clavicles; the enlarged portion in the ventral midline is the fundament of the presternum. This is conclusive evidence that the presternum is intimately associated with the shoulder-girdle in the earliest ontogenetic stages in the mammals, just as they are also phyletically bound together in the evolution of the vertebrate shoulder-girdle (infra).

The mesenchymatous material extending from the scapulae to the presternum (fig. 5) is the track in which the clavicles will soon develop. In the human embryo (fig. $6, c l$.) this has already commenced on one side. According to Gegenbaur and his followers, the core of the clavicles is the old cartilaginous precoracoid of the Amphibia. If it be true that the clavicles do have a precoracoidal core of cartilage, as Gegenbaur thought, here is the coracoidal extension in the human embryo reaching the presternum in the ventral midline, just as it does in Hexanchus, Amphibia, Reptilia, Aves, Monotremes, and fetal Marsupialia (infra).

Gegenbaur's clavicle containing a precoracoidal cartilaginous core has been attacked in several papers by Broom, who denied the presence of any cartilage in the earliest stages of the clavicle. However, Broom admits that cartilage does appear at a later stage in the development of the clavicle, and it may be assumed that cartilage appearing either as a clavicular basis (Gegenbaur) or at some later stage (Broom) would in this region in highest probability be coracoidal tissue. This position is strengthened when it is recalled that in the Anura a precoracoid actually functions as the core of the dermal clavicle. Huntington ${ }^{3}$ is

\footnotetext{
${ }^{3}$ From a private communication containing Huntington's views on several shoulder-girdle problems, kindly prepared and sent to the author October 30, 1918.
} 
the latest defender of the Gegenbaurian hypothesis, and, going a step further even than Gegenbaur, declares that in the case of the frog's girdle there is a "preparatory action on the part of the coracoid cartilage directed toward the reception and assimilation of the corresponding dermal accession of the clavicle."

In later stages of the mouse and human embryos, after the mesenchymatous girdle has become broken up into its component parts, the coracoid process is relatively much larger than in the adult and has a medial and ventral extension. I have observed this repeatedly in embryos of pigs, mice, cats, and man. In one mouse embryo, $7.75 \mathrm{~mm}$., there seemed to be a distinct thickening of the mesenchyme between the very large coracoid process and the yet partly mesenchymatous clavicle. This was a striking spectacle in the pig, because of the well-known fact that in the adult no coracoid process is present, but only the subcoracoid, glenoid-sharing portion.

\section{Sternebrae}

The segmentation of the sternum into sternebrae occurs late both in phylogeny and ontogeny. A glance through the figures in the literature assures one that sternebrae are unknown in four of the five classes of vertebrates, being found only in the mammals. Hence they play little or no part in the origin or development of the sternum phyletically.

Likewise, they are a secondary and acquired character in ontogeny. It is contrary to all expectation, if sternal bands are derived from ribs, to find that the sternebrae are invariably intercostal, and not at the point opposite the ends of the ribs. Figures 7 to 10 show what is the true condition in all fetal mammals as regards the formation and ossification of its sternebral elements. The center of ossification always occurs at a point midway between two ribs, while the line of transverse division crosses the sternum exactly in the center of the area of union of ribs and sternum. According to Ruge's theory, this should be just the reverse. The sutures between the sternebrae should be intercostal, the sternebrae themselves opposite the costal cartilages. 
Furthermore, if the sternum is ossified from the ribs, segmentation of that structure should be apparent at its earliest appearance. On the contrary, however, the sternal bands exhibit no trace of segmentation until a late period of development. The bands may. be followed carefully from section to section, or the parts reconstructed in wax, but no one has ever reported the slightest indication of an early division of the bands into segments.

The sternebrae may be interpreted as arising by a process of segmentation in response to the demand for as great a measure of elasticity on the ventral side of the animal as is allowed by the more or less flexible vertebral column on the dorsal side.

Sutures arising in this manner, as a response to strain, will naturally appear at the weakest parts along the sternum. At the points of attachment for the ribs the sternum is often deeply notched, weakening this region, and here, as expected, occur the lines of divisions of the sternum into segments or sternebrae. That this is the cause and manner is indicated by the fact that there are always the same number of sutures as there are pairs of ribs attached to the sternum. By cutting a typical sternum out of cardboard or a wax plate, and notching the sides for the reception of ribs, it is possible by applying a lateral strain to produce sutures or cracks across the cardboard or wax sternum, dividing it into sternebrae exactly as in the actual sternum.

In many of the reptiles and such animals as the cats among the mammals, where a long, lithe body in making its way through thick undergrowth or over rough ground is often twisted into almost an S-shape, the advantage of a segmented sternum is obvious. How large a part this plays in breathing is not so apparent, but doubtless has some bearing.

In the Primates where the semi-and upright position obtains, there is less need of flexibility, and the sternebrae tend to become fused into the three typical parts of the primate sternum. That the entire sternebral development is a secondary and late acquisition and has no bearing on the origin of the sternum is quite apparent. 
So far as I am aware, this will constitute the only explanation in the literature of the rise of the sternebrae, other than the statement that they represent the original costal contributions, which is, as we have shown, absolutely untenable.

\section{Stages in the ontogeny of the mammalian sternum}

1. Appearance of two laterally situated sternal bands, independent of ribs.

2. Appearance of a single median anterior rudiment, intimately associated with the shoulder-girdle.

3. Gradual approximation and union of sternal bands with the anterior sternal rudiment on the one hand, and with the ventrally growing tips of the ribs upon the other.

4. Gradual approach and fusion of sternal bands in midline of body to form a sternum.

5. Division of sternum into a number of sternebrae. Lines of division (sutures) always appearing opposite the ends of each pair of ribs.

6. Ossification of the intercostal sternebrae by the appearance of one or more centers for each segment.

7. Fusion of the sternebrae in Primates into three parts: manubrium, gladiolus, and xiphisternum.

\section{Conclusions}

1. That the sternal bands arise and remain as two unsegmented structures until the relatively late process of ossification begins.

2. That the sternebrae are invariably intercostal; arise by reason of functional demands for greater freedom of movement, and play no part in the origin of the sternum.

3. That in the mouse and rat embryos a mesenchymatous horseshoe-shaped girdle extends across the ventral midline; from this material are derived presternum, coracoids, and scapulae; this girdle being the homologue of the adult cartilaginous pectoral girdle of Hexanchus. 
4. That in early stages of the cat, pig, mouse, and human embryos, the sternal bands exist as well-defined, separate, mesenchymatous entities, prior to their union with the costal cartilages, thus indicating their independence of, and the secondary nature of their relation to, the ribs.

\section{THE PHYLOGENY OF THE STERNUM}

Paterson's comparison of the "continuous bar . . . . across the middle line" in the rat with the cartilaginous scapular arch of Acanthias, suggested the idea of following this structure found by Haswell, and later independently by Parker, in the middle ventral line of the shark Notidanus and identified by them as a presternum, up through the various groups of vertebrates to see how nearly it could be carried up in a phylogenetic series to the rodents, in which Paterson thought he had detected it again. For this purpose recourse was had to all available figures extant in the literature, and especially to that monumental monograph on the shoulder-girdle and sternum, by Parker ('68). From these sources a series of figures has been adapted, beginning with Parker's ('91) figures of the presternum in the shark, and including one figure from the Ganoids, and one each from the Teleosts and Dipnoi; then numerous figures from the Amphibia, Reptilia, Birds, and Mammals. Such a search through the literature, though wearisome, has rewarded the labor far beyond any expectations.

It is believed that the evidence presented in this phylogenetic survey would alone go far toward convincing any one of the truth of the conclusions arrived at in this paper, even though it were not preceded by the corroborating evidence of the section on the ontogeny of the sternum. It is the hope of the author that it may lead to a general agreement as to the homology and origin of the mammalian sternum.

\section{Fishes}

It is pretty clearly demonstrated by Haswell ('84) and also by Parker ('91) that at least in one shark there is a presternum 
derived from the ends of the coracoidal portions of the usually single continuous pectoral girdle characteristic of sharks. Figure 11 shows the girdle of Notidanus from the ventral side with the "intercepted cartilage . . . . temptingly like a presternal" (Parker, '91).' Figure 43, the first of the series of girdles shown in plate 12 , is another drawing from the same form. It would seem that here is the initial material from which all later presterna might possibly be derived.

The author is of course aware that neither Notidanus nor any other living shark is the direct ancestor of the vertebrates, and that the following phylogenetic series of figures does not necessarily mean that the successively higher animals are direct descendants of those immediately lower which are used for illustrating the points.

Among the teleosts a complete girdle across the midventral line is ordinarily lacking. However, several do have the clavicles prolonged toward the center, and when so, there is quite uniformly a cartilaginous element in the midline which Parker ('68) calls the 'epicoracoid.' ${ }^{4}$ This lies between the coracoids, in the identical position of a presternum. It is interesting to note from figures $12,13,14$, and 15 , that this condition is so closely alike in a ganoid, Polypterus (fig. 12); a teleost, Gobius niger Linn. (fig. 13); and a dipnoan, Lepidosiren (figs. 14 and 15). A description of the condition in these three fishes may be given in the account of Parker ('68) for that of Lepidosiren annectens: "Lepidosiren agrees with the elasmobranchs in a well developed epicoracoidal belt. Originally the epicoracoid mass must have been double, and perhaps in a very early stage each moiety was continuous with the coracoid proper, but a wide transverse cleft was soon formed which separates epicoracoid and coracoid."

${ }^{4}$ In this paper the term 'epicoracoid' is employed to designate the cartilaginous ventral ends of the posterior coracoids. The author is following here the usage of Parker and others from whom many of the figures have been borrowed. That this is not the correct term, he is well aware, and in another paper is suggesting the term 'infracoracoid' as probably a more suitable one for these parts. The term 'epicoracoid' was applied to the anterior element of the monotremes by Cuvier, and this use should be retained. 
Figures 14 and 15 show the epicoracoid to have a large midventral portion, rounded out anteriorly and posteriorly (comparable directly with the so-called presternum of the shark and the omosternum and sternum of the Amphibia), while laterally extend two bars, the parts which originally were continuous with the coracoids. Here there is cut off from the coracoids that material which nature will use in all higher classes of vertebrates in the construction of a presternum. And if it be said that this dipnoid fish is not the direct ancestor of the Tetrapoda, it may be replied that every consideration points to the same condition in the direct ancestor, whatever form it was. Both Paterson, in the rat, and the author, in the mouse, found stages in early embryo of these mammals where the clavicles, extending toward the midline, are closely invested with mesenchymatous bars which unite into a single, median mass, comparable at once to this epicoracoid in the dipnoid fish and to the 'presternum' of Haswell's shark, and actually in the rodents uniting to form the manubrium.

\section{Amphibia}

A similar sternum is found in the Amphibia. As Howes remarks, "that the Amphibian sternum is for the most part, if not wholly, a derivative of the shoulder-girdle, there can be no longer a question; and although the researches of Goette ('77) leave us in doubt concerning the hypo (post-omosternum) they show that that can be no derivative of the costal apparatus."

Parker ('91), believing in the diverse origins of the sternum in the Ichthyopsida and Amniota, also describes a dual origin for the sternum in the Amphibia. He says, "a pair of narrow strips are separated off from the posterior borders of the coracoids," also "a pair of cartilaginous bands appear in the inscriptiones tendineae of the mm. recti abdominis. From these four elements the sternum is produced." Ruge considers that these cartilaginous bands are to be looked upon as vestigial ribs. The narrow strips are admitted to be from the shouldergirdle. 
This description of two cartilaginous bands appearing in the inscriptiones tendineae is strikingly similar to the account of the sternal bands in the pig by Whitehead and Waddell. There seems to be no antagonism anywhere to the view that in the Amphibia the anterior part of the sternum is the product of the shoulder-girdle.

Nor is it necessary to stretch any morphological relations unduly to see this coracoidal sternum reproduced in the Dipnoi, Gobius, Polypterus, and Notidanus. We must agree with Parker ('91), Haswell ('84), and others, that the sternum in the Ichthyopsida is coracoidal in origin and homologous throughout that group.

From here on, however, we part company with all early workers, and most later ones as well, for all of them accept Ruge's conception of a costal sternum in the Amniotes, and deny any homology between the sterna of Ichthyopsida and Amniota. One of the designs of this present phylogenetic sketch is to show from figures and data already in the literature that the two are one and the same thing in origin and development, and therefore homologous.

As practically all are agreed that the sternum in the Amphibia is coracoidal in origin, while but few are agreed that it is so in the Amniotes, we are brought to the necessity of bridging in some manner the alleged gulf between the amphibian and reptilian sternum.

In order later to make direct comparisons between amphibians and reptiles, when treating the latter group, it is necessary to introduce here a number of figures and remarks thereon for several representative amphibians. Starting with the frog, figures 16 to 19 , inclusive, give a very good idea of the development of the coracoids and sternum in this form. It is hardly necessary to point out the close relation between coracoid and sternum nor to suggest that the figures can lead only to one conclusion, that of a coracoidal origin for the sternum.

Pipa (fig. 20) has a sternum which, as Parker says, challenges attention. A little study of this figure will convince one that the sternal region must have been at one time a part of, and 
continuous with the epicoracoids. The ossification in each is at exactly the same stage; the amount of soft cartilage around the edges is the same in coracoid and sternum. At the anterior end is differentiated a small region that corresponds to the larger omosternum in the frog. We shall come back to Pipa when treating some of the reptiles, and by a comparison attempt to show that this subreptilian creature has a sternum essentially like certain reptiles.

Does Bufo (fig. 21) have a sternum? Kingsley ('17) would say that since no ribs are in this region, no one can say. On the theory of Ruge, this would be true, but if we compare the sternum of Bufo with that of Pipa and the early stages in the frog, it is hard to believe that there is any essential difference between the two structures, although the connection of the sternum with the epicoracoids in Bufo is not so extensive as in many other Amphibia. The entire body of evidence in this paper and many others on the shoulder-girdle in the Amphibia can only lead to the conclusion that Bufo does have a sternum and that it can only be derived from the coracoidal portions of the shoulder-girdle.

Siredon (fig. 22) has large coracoids and a considerable overlapping of their epicoracoidal edges. The interesting feature to us is that the sternum lying immediately behind the overlapping epicoracoids also shows very distinctly two grooves corresponding exactly to those made by the overlying edges of the epicoracoids. It is the condition precisely to be expected of the sternum if it were in an early stage a posterior continuous extension of the cartilage, sharing in the overlapping, and then later had been cut off by sutures from the main element, but retaining these evidences of its formation from the two epicoracoids.

Little need be said concerning such a girdle as that of Dactylethra (fig. 23). There is no overlapping of the coracoids and no sutural evidence in the sternum of the union of the two sides; however, as this is an adult specimen, none need be expected. Nevertheless, the intimate relation of sternum and girdle is evident.

In Calamites (fig. 24) we see a sternum that for the first time 
has two backward prolongations, or sternal bars. This sternum is very suggestive of several in the reptiles, and embryos of the mammals, where a single median anterior rudiment is continued backward as two rods or bars. This is an adult specimen and therefore the permanent form in this species; if, however, we compare this with several of the reptiles, such as shown in figures 26, 27, and 28, and with descriptions by Rathke, Bruch, Paterson, etc., of the early sternum in the mammals, there appears to be more than a mere resemblance- - there is genetic relationship and homology. If in Calamites the coracoids were to retreat to a mere process attached to the scapula, leaving only the clavicle and sternum in this region, and the sternal bars of the latter fused together in the midline, leaving a fossa at the upper end of the union as in many reptiles, and the posterior ends were but incompletely fused leaving two small blunt laterally projecting horns, we would have a sternum such as is actually found in Chirotes (fig. 30) and the embryos of mammals.

Wilder ('03) describes several cartilaginous rudiments found in Necturus and related by him to the sternal apparatus. These are a series of thin cartilages located in the myocommas of the pectoral region. One of them is usually larger than the rest and situated near the posterior part of the overlapping coracoids. This element is identified by Wilder as the homologue of the sternum of the higher Urodeles.

If Wilder's theory be correct, Necturus presents an exception to the rule established in this paper that the presternum is a derivative of the coracoids, for obviously this element in Necturus could not possibly be derived from that source. My own dissections of Necturus, however, do not bear out Wilder's hypothesis. My interpretation of these cartilages is, that they are simply chrondifications of the outer part of the connective tissue of the intermuscular septa and have no relation whatever to the formation of the presternum in higher forms.

They are rather to be looked upon as subcutaneous splints and find their homologues in the inscriptiones tendineae of other forms, and also possibly in the abdominal ribs of Chamaeleo and Polychrus. It is significant to note in this connection that many 
animals have both the inscriptiones tendineae and also a complete sternal and costal apparatus. If the latter be the derivative of the former, why this persistence of the two structures side by side in nearly all groups above the lower Urodeles?

\section{Reptiles}

Fossil reptiles constitute the next group in which we have looked for a sternum or any part of one which either originates independently of the ribs or which has intimate relations with the shoulder-girdles. The author has studied figures and plates of much of the recent work done on fossil reptiles, of which the investigations of Credner ('81-'93), Gregory ('15), Seeley ('92, '94), Woodard ('98), and Zittell ('00, '13) are typical, and, in addition has examined a number of mounted specimens in the U. S. National Museum. It may be said in general that in those skeletons which have the shoulder-girdles preserved there is a strong tendency for the coracoids to grow around the side of the body ventrally, though never meeting in the midline, for the soft epicoracoids are not preserved, and that the coracoids are enormously developed in size.

Gunther ('67), Schauinsland ('00), and Howes and Swinnerton ('01) worked on the development and anatomy of that primitive and now almost extinct reptile from New Zealand, Hatteria punctata or Sphenodon. In one of Gunther's figures the shoulder-girdle and sternal bars are shown in their natural relation at thatstage. The coracoids do not have a large ventral extension, but are capped on their medial ends by slender processes which later unite to form the presternum. Three pairs of ribs reach each sternal bar, so that the sternal and costal connections are much too far advanced for any statement as to the origin of the sternal bars in Sphenodon. So far as I am aware, this is the youngest stage of the Sphenodon sternum figured in the literature.

From the condition in the embryos of living reptiles, as well as in many of the adult species, it may be assumed that in the early condition of fossil reptiles the coracoids were in intimate relation to the sternum. 
When we come to consider the living reptiles the material and evidence is abundant and of the greatest significance.

Among the recent forms, Goëtte ('77) has studied Cnemidophorus. While he does not show conclusively that the two anterior triangular rudiments are products of the nearby coracoids, he demonstrates that only the first ribs have reached and attached themselves to the sternum, while that part of it opposite the second and third ribs is formed independently of them, as a backward prolongation of the anterior paired rudiments.

These results of Goëtte showing that the sternum is the result of a backward growth of tissue from an anterior portion are in striking anticipation of what Paterson claimed to see in the rat, where it is stated that the anterior median portion of the sternum is derived from the same element as is the shoulder-girdle, and this in turn yields the sternal bands as posterior prolongations.

Anguis fragilis (fig. 25) has a sternum that in many respects is typically amphibian in character, as may be seen at once by a comparison of this form with that of Pipa. As in Pipa, there is only present an anterior or presternum, separated by sutures only from the epicoracoids, and as in Pipa, ossification and the amount of soft cartilage around the borders are the same for sternum and coracoids. Of this form Parker ('68) says, "there is a well developed sternum, not continuous with the ribs;" and Rathke, describing two embryos of Anguis, says, "with the coracoids the sternum was intimately united, but it was not very closely connected with the neighboring ribs, lying at a much greater distance from them than in adult Blindworms. There cannot be any doubt that in the Blindworms the two latter halves of the sternum do not originate under the ribs, and unite with them, but develop at a distance from the ribs." Barring the presence of the interclavicle in Anguis, it would be difficult to recognize this shoulder-girdle as being that of a reptile, for in the relations of its girdle and presternum and in the absence of ribs it is characteristically amphibian.

Stellio cordylinus (fig. 26) has a sternum in which the anterior part is enormously enlarged; is in intimate relation to the epicoracoids, and in addition has two greatly extended xiphisternal 
horns. No ribs are attached to these horns, but three pairs reach the anterior portion, to which they are but feebly attached. If it be assumed that the presternum here is of necessity derived either from the coracoids or from the ribs, the answer can only be that it must have come from the former. This sternum with its great horns reappears in Manis longicauda (Parker, '68).

A series of three figures (figs. 27, 28, and 29) gives an idea of how the mesosternum and xiphisternum are formed. In figure 27 the presternum is as before, and the two bars extend caudally. This is very similar to the amphibian Calamites (fig. 24), and the suggested series of changes outlined in the description of Calamites necessary to make of it a typical reptilian or mammalian sternum are progressively illustrated in these three reptiles.

In figures 28 and 29 the xiphisternal bars, by a fusion along their medial surfaces, have formed a middle sternal piece or mesosternum. The posterior ends of the coalesced bars remain apart in the xiphisternum.

In the mesosternum is a sternal fossa, where the union was not complete. This may persist throughout life in many forms (Varanus, Crocodilia) or, as in others, close up later, leaving a whitish streak to indicate the line of fusion. This fontanelle is also common in mammals, but there it is usually located in the xiphisternum, and I have also repeatedly observed the whitish streak of hyaline cartilage in the mesosternum in fetuses of pigs and mice. It would seem from this reptilian material, and avian and mammalian material agree, that the presternum is a product of the coracoids, and this in turn gives off two backward prolongations, which, fusing throughout a greater or lesser part of their extent, form the mesosternum and xiphisternum. It is hardly necessary to again point out the feeble relation of ribs and sternum in these last three figures.

Chirotes (fig. 30) gives the completion of the series; it is a sternum of the utmost importance in the consideration of the problem. Parker's description is so trenchant that a part is quoted:

In the whole range of vertebrate morphology there is nothing more beautiful or more instructive than the relatively large sternum of Chi- 
rotes; for if the sternum of the human embryo were to be demonstrated apart from the costal girdles, one diagram would serve to explain both that and what we find in this little snake-like lizard . . . . and if ribs had not been arrested we might have seen the counterpart of the ribs of the mammalian embryo.

The figure is of an adult, and, as Parker says, it might also be described as that of the mammalian embryo, except that no ribs are present and the sides of the presternum are closely applied to the coracoids. Now, if Paterson and the author be correct in their contention that the presternum and coracoids in the rat and mouse are continuous at an early stage, and this stage precedes the fusion of ribs and sternum, then the adult Chirotes sternum is a structure that far more closely approximates the early embryonic sternum of mammals than Parker suspected when he made the comparison above quoted between the two. This is a more striking parallel than is usually met between the adult structure in a lower group and an embryonic stage of the same structure in a higher group.

While probably all will admit the above argument, since both are Amniotes, the question may be raised as to whether there is any evidence for relating such a sternum as occurs in Chirotes with the amphibian sternum, for the crux of the whole matter of sternal homology lies between these two groups. It would seem that a direct comparison might be made with the Calamites sternum, and this structure, as has already been indicated, by a fusion of the sternal bars, and a retention of the sutural relation to the epicoracoids might be metamorphosed directly into the adult sternum of Chirotes, and this is especially strong evidence when we consider that in neither the reptile nor amphibian compared does the question of ribs enter at all, since there are none in either form in the region of the sternum.

Using the crocodile (fig. 31 ) as a contrast to Chirotes in showing the extreme of fusion of ribs and sternum in reptiles, it may be remarked at once that aside from the presence of ribs this sternum is directly comparable with the last one considered. The difference is due to the ventral growth and attachment of ribs to the sternum, otherwise it is essentially the same as more primitive 
reptilian sterna having a presternum in close conjunction with the coracoids; a middle piece composed of the union of two longitudinal bars, with the line of fusion clearly evident, and the xiphisternal horns wide spread. A close comparison may be made between this and the later stages of the mammalian sternum, except that in them all connection with coracoids is early lost.

A Chamaeleo vulgaris adult sternum (fig. 32) is the last reptile considered here. It is mammalian-like and well ossified for a lizard. The presternum is a large, lobate structure, bearing two strong notches on either side on its posterior end, "this constriction answering to the transverse cleft so constant in the mammalian sternum" (Parker, '68). In the mesosternum the line of fusion of the two halves is well marked and extending also into the presternum. The ribs articulate by synovial joints with a series of enlargements on either side of the mesosternum. In describing the xiphisternum, Parker ('68) says, "The xiphisternum has a bilobate extremity that is quite mammalian in character and no ribs ever reach this part . . . . the horns being free from ribs, grew not only towards each other and fused, but also grew backwards, so as to form a free, single xiphisternum, exactly like that of an ordinary mammal. That there is no real difference between these two classes in the formation of the xiphisternum, I feel certain.

The interesting fact about Chamaeleo is the statement of Parker that behind the xiphisternum there are seven pairs of floating ribs which later become fixed by growing toward each other and unite by suture at the midline. This is significant in the light of our contention of the non-relationship between pleural ribs and sternum. There is a distinct tendency in all vertebrates with ribs for these to grow ventrally. Now, if a sternum be present, it is likely that they would form an articulation with it; if none is present, that they should either remain free (floating) or unite (true ribs) with each other in the midline. In the chamaeleon both conditions are present in one animal; those anterior thoracic ribs which, growing ventrally, met the sternum and articulated with it, while those ribs immediately behind the 
sternum kept on growing until the respective pairs met and fused in the midventral line. Chamaeleo is considered to present strong evidence of the secondary character of the relation between ribs and sternum, and it is an important intermediate stage in the development between the typical reptilian sternum and the same structure in the mammals.

The preceding account of the development and anatomy of the sternum in the Reptilia and a comparison with the same structure in the Amphibia must inevitably lead to the conclusion that, if the presternum be coracoidal in origin in the Amphibia, it is equally so in the Reptilia. For, beginning with that most primitive reptilian sternum in Anguis, and comparing with Pipa and other Amphibia, the gulf was bridged between these two phyla, and then by a series of successively more highly developed sterna in the reptiles a stage is reached (Chirotes) which spans the divide between the reptiles and mammals. We have also seen how in one amphibian (fig. 24) the beginning of sternal bands arises, and in the reptiles these are developed in the same way, and in higher reptiles fuse to form the mesosternum and xiphisternum, preparing the way for the typically mammalian sternum, soon to be considered.

The last fact concerning the Reptilia is in regard to the extremely variable relation of ribs and sternum, both as to number and position. Rathke ('53) had an interesting paragraph on this which is quoted in part:

In typical scaly lizards several ribs are always in relation with the sternum; still . . . . it may be either only the anterior division (manubrium) which is connected with ribs, or it may be exclusively the posterior part. But, generally speaking, the number of ribs which are intimately connected with the sternum, and to which the name of true ribs can be applied, not only varies with the genus, but is also very variable in different species.

Both Rathke and Parker give long lists of species of reptiles showing this variability in the number and position of ribs reaching the sternum. Their lists comprise some fifty species, but only a few are mentioned here as indicating the range of variation found by them. Their figures show that in some species 
with the largest number and most intimate union of ribs to breast bone the sternum is but feebly developed; while, on the other hand, some of the largest sterna have the fewest number of ribs and feeblest connection of the two; or, as in Chirotes, a fully developed sternum showing the three typical divisions is present, but no ribs reach the sternum-conditions hardly to be expected if the ribs contribute the sternal materials.

The following table is a composite one from several authors and shows but a few of the numerous forms they list.

\begin{tabular}{|c|c|c|}
\hline & $\begin{array}{c}\text { RIBS TO } \\
\text { MANUBRIUM }\end{array}$ & $\begin{array}{c}\text { RIBS TO } \\
\text { MESOSTERNCM }\end{array}$ \\
\hline Chiroteŝ canaliculatus...................... & 0 & 0 \\
\hline 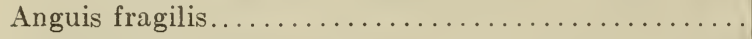 & 0 & 0 \\
\hline Chamaeleo pumilis.................... & 1 & 0 \\
\hline Monitor dracaena.............. & 2 & 1 \\
\hline Draco viridis................... & 3 & 0 \\
\hline 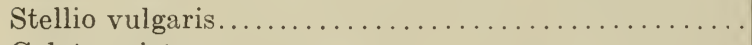 & 3 & 1 \\
\hline 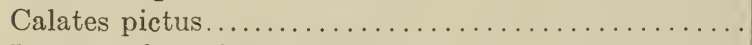 & 3 & 3 \\
\hline 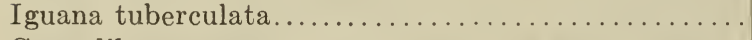 & 4 & 2 \\
\hline 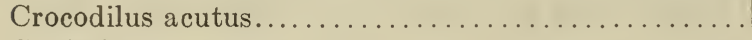 & 2 & 5 \\
\hline 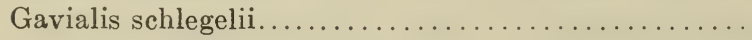 & 2 & 7 \\
\hline
\end{tabular}

\section{Birds}

Birds, although not in the line of descent of the mammals and also having a sternal apparatus highly modified for purposes of flight, are still not difficult to bring into line in this argument. However, it is hardly necessary to do this as we are following successively more complex and highly differentiated groups in their phylogenetic course. Nevertheless, to show that there is nothing contradictory to our thesis among the birds, one figure of a bird is introduced. This is Vanellus cristatus (fig. 33) and is of a stage at the end of the first third of the incubation period. Parker's remarks upon this sternum give us the pertinent facts: "The longitudinal bands are long and wide, and in great contrast to the very slender pairs of ribs attached to them. On the other hand, a transverse cleft between the epicoracoids and the anterolateral margins of the longitudinal bands would give us the con- 
dition as here found. The sternum of Vanellus is not a highly complex structure, as such structures go in the higher birds, but shows many affinities to the reptilian stock."

It would be absurd to think that these large, heavy sternal bands were originally derived from the feeble and loosely attached pairs of ribs, while it is entirely plausible to suppose that in an earlier stage a continuous sheet of cartilage on either side was subsequently differentiated into sternal bands, coracoid, and scapula. That this is actually the state of affairs in early embryos of several mammals will soon be shown.

That the development of the sternum is largely independent of ribs in the birds, as in reptiles, is further shown by Parker's observations on Apteryx:

In the earliest stage in which the sternum is present it extends backwards to the level of the third thoracic rib; the first two ribs are united to it by joints, the third loosely attached by connective tissue. In the next stage, the first three ribs are attached by joints, and the fourth by connective tissue, that is, as it appears to me, the portion of the sternum corresponding to the third and fourth ribs is formed by a backward growth of the anterior region and quite independently of the last two ribs (italics mine), the union of which with it is a secondary process.

This is just about what Paterson says concerning the development of the sternum in the rat, except that it leads him to conclude that the sternum is not of costal origin, while Parker, giving all the evidence necessary to substantiate Paterson's view, is nevertheless himself oblivious of the logic of his own work, and makes the surprising statement that "the relation of the shoulder girdle to the sternum is altogether secondary, and forms no part of the axial skeleton, as the Transcendentalists vainly teach."

The above account of conditions in the birds seems to be sufficient to relate genetically the sternum in birds to that of reptiles and mammals, and while of little or no philogenetic value in this connection, yet the evidence shows the avian sternum to be homologous with the sterna throughout the entire vertebrate series, one of the theses for which this paper contends. 


\section{Monotremes}

The monotremes (fig. 4) have long been held to have a sternum closely reptilian in character. In addition to the coracoids, which are firmly attached to the sternum, there is also an anterior paired element, usually called the epicoracoid. In these there is an overlapping in the midline much as in certain amphibians, and in a recent paper Watson ('17) holds that the epicoracoids of the monotremes are nothing other than the precoracoids of the lower forms. That typically reptilian structure, the interclavicle, is also present. As seen in the figure, there is noticeable a compactness of the elements of the shoulder-girdle and sternum, as if these might have been in the early embryo or in the ancient progenitor a single shield-like plate, such as occurs in Pipa (fig. 20) or in many of the reptiles.

\section{Marsupials}

In 1897 Broom discovered in the marsupial Trichosurus vulpecula, measuring $17 \mathrm{~mm}$., a well-developed coracoid, which was at birth "structurally continuous with the sternum." Figure 35 is an anterior view of the entire scapular arch which in general outline is strikingly like that of the shark. Its ventral middle portion is a part of the sternum, yet the parts are, as Broom says, not jointed, but constitute a single bar of cartilage.

In a smaller specimen (fig. 36) of $8.5 \mathrm{~mm}$. of the same animal both cartilaginous and mesenchymatous elements are present in the coracoid; the cartilaginous part being that nearest the glenoid cavity, and the mesenchymatous spreading out in a fan-shape portion, which is continued without any interruption into the mesenchymatous sternum. It is apparent that this marsupial has a complete scapular arch crossing the middle line; and that, from the history of the later stages, the sternum as well as the girdles are known to be its derivatives. Furthermore, just in front of the coracoid and posterior to the clavicle, there was "a thin, feebly developed continuous sheet of mesenchymatous cells;" lying therefore in the exact position of that anterior coracoidal element of the monotremes generally called the epicoracoid, 
but by some the precoracoid. That the two structures, i.e., the epicoracoid of the monotremes and this "sheet of mesenchymatous cells" are homologous is the belief of Broom. In the larger specimens (37 $\mathrm{mm}$. and over) the coracoid becomes detached from the sternum by a process of degeneration, and this continues until the well-known adult condition is reached (fig. 37) where coracoids and sternum are far apart.

However, in a mammary fetus $23 \mathrm{~mm}$. long an intermediate condition was found. As Broom describes it:

The coracoid process is similar to that in the large foetus, but from it there is produced backwards and inwards a small cartilaginous process, which nearly meets the outer process of the presternum. It may thus be concluded that during the later intra-uterine development of Trichosurus, and probably of other marsupials (later verified in other marsupials), there is a well developed coracoid, which, as in the adult Monotremes, most reptiles, birds, and amphibians, articulates with the sternum, and that shortly after birth, the coracoid loses its attachment with the sternum, and becomes rapidly absorbed, only the anterior part remaining as the coracoid process..

From this description it appears that the degeneration of the coracoid begins in its middle part and absorption progresses toward each end. In the marsupials that part of the coracoid attached to the sternum is completely absorbed and no trace of it is found in the adult, while the half connecting with the scapula is represented in the adult by the coracoid process. In this connection mention may be made of a peculiar structure I find in the mouse and rat, and an almost constant structure in rodents, as figured by Parker ('68). In most of his figures of the Rodentia, there is a small bony process on either side of the presternum between the juncture of the clavicle and the first rib with the sternum (fig. 38). Parker calls this process the epicoracoid and says it was left by the retreating coracoids of the lower forms. It would seem from my observations on the mouse, described above, that Parker is correct to the extent that this is the median end of the coracoid, but wrong in making it simply an hereditary rudiment. It is, rather, the end of a complete embryonic coracoid, which in the rat, mouse and man, as in the marsupial, extends across to the sternum in an early stage. Whereas in the 
marsupial and most other mammals, all trace of this sternocoracoidal piece is lacking in the adult, it persists in the rodents, and also in the narwhal (Monodon monocerus), and the blackfish (Globicephalus melas), and possibly other animals. In other words, in the rodents there is at first a complete coracoid reaching from the scapula to the sternum; later, degeneration of the coracoid sets in at its middle portion, and working toward each end, stops just in time to leave the coracoid process attached to the scapula and the epicoracoid to the sternum.

From the foregoing it is apparent that Trichosurus passes through a stage in its development, as regards girdles and sternum, which is directly comparable with that of the adult condition in the monotremes.

In a series of later papers ('98, '99'02,'08) Broom studied a number of marsupials, both Polyprotodonts and Diprotodonts, and found that conditions throughout the Marsupialia were as described for Trichosurus. In a mammary fetus of the common phalanger, $14 \mathrm{~mm}$. long, the well-developed coracoid articulates with the sternum almost exactly as in the adult monotremes. In the earliest stage of Dasyurus (fig. 39) studied by Broom, the coracoid is still large and reaches nearly to the sternum. It would seem that here absorption had commenced at the medial end rather than in the middle of the cartilage. Figure 48 (petrogale) shows a complete, unjointed arch similar to that of Trichosurus. Pseudochiurus and permales were studied in various stages and agree in general with other marsupials, so that this is obviously a normal and constant phenomenon of the marsupial embryonic girdle, as it is of the adult girdle in the monotremes.

Prior to Broom's work, it was difficult, practically impossible in fact, to pass from the monotreme shoulder-girdle to that of the marsupial, albeit the relationship of monotreme girdle to that of the reptile was apparent. Since Broom's discovery, however, of the complete girdle in the early marsupial, and also in the rat by Paterson and the mouse and man by the present author, it is clearly seen that the girdles and sternum of the higher mammals are directly comparable to that of the marsupial fetus, and this in turn to the girdle of monotremes, which are unquestioned in 
their reptilian affinities. It is thought that this makes a strong case for the homology of the sternum in the Amniota and its origin in connection with the coracoids; and since this same structure is undoubtedly coracoidal in the Ichthyopsida, the two, Amniote and Ichthyopsidan sternum, are homologous.

As this work of Broom's is of considerable importance to our argument, it may be stated that Broom in his later papers verified his first discoveries in representatives of all groups of marsupials and made graphical reconstructions of the parts. His work has been checked up by Watson ('17), who made wax models of the girdles and sternum, and completely confirmed Broom's results.

\section{Aquatic mammals}

Among the aquatic mammals there are several interesting sterna. In the adult Manatus americanus (fig. 40) the sternum is moderately large and is typically divided into the usual three parts. This animal has seventeen pairs of ribs, but only three come anywhere near the sternum, and Parker ('68) says that only the second pair of ribs reaches it. The first and third pairs are connected with it by ligament only. Here in this adult mammal is a stage comparable to the embryo of the pig, man, etc., where ribs either do not reach the sternum or are connected with it by fibrous tissue. It is difficult to believe that this entire sternum was derived from the costal ends of three pairs of ribs, of which only one pair even approaches it.

According to W. K. Parker ('68) the sternum of the dolphin embryo (fig. 41) has reached its highest development in aquatic mammals. In the stage figured the sternal bands have fused, leaving a prominent longitudinal groove to mark the line of fusion, several centers of ossification are present, and in the presternum is an oval fontanelle such as is common in the lizards. In fact, this entire structure is very reptilian in character, as is seen by a/comparison with Trachydosaurus (fig. 28), even to the number of ribs.

In orders of mammals higher than those already mentioned the literature is scanty. Practically all papers based upon the 
human embryo accept Ruge's view, and the reason is apparent when we consider that in working exclusively with the highest mammals, one is at the disadvantage of not knowing what stages may have been suppressed in evolution. It would seem that, beginning with the lowest forms and working up through each successive group, as is attempted in this present paper, a foundation is laid upon which to interpret the greatly reduced history in the higher mammals.

Does the complete girdle, sternum, coracoid, and scapula, cross the midline in forms higher than the marsupial? Since the permanent adult coracoid articulating with the sternum in the monotreme is reduced to only a fetal stage in the marsupial, we might expect this stage to be very transitory or entirely suppressed higher in the scale. Since the marsupials, edentates, rodents, and insectivores are all ancient orders and probably lie not far from the monotreme stem, among them such a stage might be found, if present. Paterson was the first to discover this in an early embryo of the rat, and I found the same thing (section on ontogeny) in the mouse of 7.75-mm. and 17.2-mm. human embryo. This is shown in figures 5 and 6 , where the girdles are very similar indeed to that of a shark (fig. 2). The next stages indicate that scapulae, coracoids, and sternum are all derivatives of this single mesenchymatous element. This stage is exceedingly brief in the mouse, as compared with the marsupial, for it cannot be detected with certainty in a $6-\mathrm{mm}$. mouse, and is hardly recognizable in the $8.75-\mathrm{mm}$. mouse. This rapid suppression would lead us to suppose that possibly no such stage is present in the human embryo, yet figure 6 shows man to have retained it identically as in the rodents.

Huntington ('18) identifies the costocoracoid ligament of man as indicating "the original path of the sternal extension of the coracoid." It is interesting in this connection that the costocoracoid ligament often contains fibrocartilaginous nodules. Figure 42 shows this ligament in relation to the other parts in man on the left side of the figure, while on the right side, the fundamental plan of the vertebrate girdle as illustrated in the Anura is shown. Huntington does not say whether he considers the 
costocoracoid ligament to be the remains of an embryonic coracoid occurring in man or only the rudimentary indication of man's phylogenesis. If this interpretation of the costocoracoid ligament as the evidence of a coracoidal connection with the sternum be correct, then from the elasmobranch to man the closest relation between coracoids and sternum is maintained. On the other hand, if Huntington's hypothesis is not sustained by later investigation, no harm is done to our attempt to overthrow Ruge's theory, for Rathke, Paterson, Whitehead and Waddell, and myself have already shown that in man and other mammals the sternum is an established structure prior to the union of ribs with it.

\section{The adult human sternum}

In the literature of the adult sternum in man there is evidence of a secondary, but interesting and corroborative sort. It may be related back to the tendency of the ribs to grow toward - the ventral median line and fuse or articulate with each other, as was noted in Chamaeleo. This has been shown by several workers, Cunningham ('90), Dwight ('90), Tredgold ('97), Paterson ('09), and Lickley ('04), to be especially prominent in the human subject. Lickley, whose work is typical, studied a series of fifty-one human sterna with special reference to the relations of the seventh and eighth ribs to the sternum.

The number of ribs reaching the sternum in Lickley's material is shown in the following table:

\begin{tabular}{|c|c|c|}
\hline & RIGHT & LEFT \\
\hline Sixth $\operatorname{ribs} . . . . . . . . \ldots$. & 2 & 1 \\
\hline Seventh $\operatorname{ribs} . \ldots \ldots \ldots \ldots \ldots \ldots \ldots \ldots \ldots \ldots$ & 43 & 43 \\
\hline Eighth ribs. . . . . & 6 & 7 \\
\hline Total........................ & 51 & 51 \\
\hline
\end{tabular}

This constitutes a considerable percentage of variation at the posterior end of the thorax, yet whether six or eight ribs enter into union with the sternum, that structure is apparently not 
affected in length or shape. Advocates of a costal origin for the sternum derive the xiphisternum from the ends of the seventh or eighth ribs or both. However, when these are absent, the formation of the xiphisternum does not seem to be affected in the least. As in the reptiles, it is a constant feature regardless of the absence or presence of ribs.

In the work of Paterson ('09) and Lickley ('04) an even more suggestive fact is clearly apparent. This relates to the tendency of ribs to grow to the ventral side and fuse as was also seen in Chamaeleo and noted in the discussion of reptiles. In man the seventh rib normally reaches the sternum, but in its mode of attachment we have the remarkable statement of Lickley that in over 50 per cent the seventh costal cartilages are either fused or articulate with each other in a plane anterior (ventral) to the xiphisternum. That is to say, these ribs which are anterior to the posterior end of the sternum reach the median line and fuse just as did the ribs posterior to the posterior end of the sternum in Chamaeleo. In all the accounts here under review the ribs act as if entirely independent of and irresponsible for the being or well-being of the sternum.

Paterson's results are not so striking in large percentages as Lickley's, but sufficiently so to give us pause, even if considered alone. He examined 236 human fetal sterna and found that the seventh costal cartilages articulated in front of the sternum in 14.4 per cent.

In this connection three special cases may be cited, the first two reported by Lickley and the last by Dwight:

1. The sixth costal cartilages articulated dorsally with the lower end of the mesosternum and ventrally with one another. The seventh cartilages articulated with the lower borders of the sixth cartilages and by their extremities with one another.

2. Girl, eighteen years. Mesosternum terminated at level of insertion of fifth ribs. The extremities of the sixth and seventh cartilages on the left side were fused together, those on the right were closely united by fibrous tissue. The two bars formed in this way articulated with the mesosternum above, and with one another in front. 
3. The body of the sternum ends at the level of the fourth ribs. The fifth pair is attached to its lower end. The fifth, sixth, and seventh pairs meet one another and fuse.

Kirchner ('98) and Adolphi ('05) also describe sterna in large numbers and find many cases of variation in the posterior thoracic ribs much in accord with the above. The results of these papers on the adult sterna of the human subject, together with similar observations on the lower forms, which are pertinent to our thesis are four:

1. Ribs posterior to the level of the sternum may grow ventrally and meet by fusion or articulation in the midline (Chamaeleo).

2. Ribs at the level of the sternum may articulate firmly with it, as is the usual case in man.

3. Ribs may pass on the ventral side of the posterior end of the sternum and fuse in the midline much as they do when farther back where no sternum is present (Chamaeleo, man).

4. All ribs may fail to meet the sternum at any point without affecting the full development of that structure (Amphibia, Chirotes, Manatus, human embryo).

Plate 12 , figures 43 to 49 , inclusive, is designed to give at a glance a series of shoulder-girdles representing the main groups of vertebrates, in an effort to show how from the elasmobranch to the rodent, either in the embryo or throughout life, there is an intimate relation in all between shoulder-girdle and sternum, and in some it is demonstrated that they are for a time one structurally continuous element. In some (shark, lissotriton, lizard, and monotreme) this relation is maintained throughout life; in others (marsupial, mouse, rat, and man) it is of short duration in embryonic life. In all, however, it indicates a phylogenetic relationship between the shoulder-girdle and sternum in all stages of vertebrate evolution that cannot possibly be duplicated or even remotely approximated by a similar comparison of sterna and costal cartilages.

In most adult Amniotes the sternum is in close relation with both ribs and shoulder-girdle; in some, however, the connection with either ribs or shoulder-girdle may be lost (Chirotes, fig. 30, 
being an example of the first, and the pig of the second); but none is known in which the relation to both ribs and shoulder-girdle is lacking. Assuming that the sternum must be either a derivative of the shoulder-girdle or of the ribs, it is clearly evident from a phylogenetic viewpoint that since the costae verae extending to the ventral side of the body were not acquired by the vertebrates uutil the rise of the Reptilia, whereas the sternum and shoulder-girdle, in an ever-increasing closeness of relation and association, may be traced back to the very beginning of the Ichthyopsida in the elasmobranchs, that we cannot hope to find in the ribs any clue to sternal origin. If the sternum be homologous throughout, as the conclusions of this present investigation seem to warrant, then its origin may be sought in a structure which is coexistent with it and also in the closest possible relation to it in the lowest forms. In the shoulder-girdle of the Ichthyopsida we seem to meet with both of these requirements, while in each of them the ribs fail us.

In Huntington's ('18) paper, which appeared after this work was practically completed, are certain fundamental conceptions of the shoulder-girdle and its phylogenetic relationships which indirectly corroborate my conclusions. In the first place, Huntington recognizes the elasmobranch pectoral girdle as "the primordial fundament upon which all other vertebrate modifications are built." By a dual process of segmentation and replacement by bone, all structures of the complicated girdles of the higher classes of vertebrates are derived from this simple continuous unsegmented bar of cartilage found in the dogfish, sharks or rays. Huntington was not, however, primarily interested in the sternum and did not see in the midventral portion of the elasmobranch girdle the fundament of the presternum. Like other investigators, he finds the "first appearance of the sternal apparatus" in the amphibian girdle, but notes its intimate association with the epicoracoids, which latter cartilages are beginning to loosen by sutures on either side of the ventral midline. However, it must be pointed out that these structural relations of the Amphibia (clavicle excepted) are also present in Hexanchus, where a suture on either side of the ventral midline gives the 
'intercepted cartilage' interpreted by Howes ('91), Parker ('91), and myself as the rudiment of the presternum. If two dotted lines be added to the Hexanchus girdle (fig. 1), a sternum comparable to that of Rana is produced, with epicoracoids meeting in the midline and the fundaments of the omosternum and sternum present.

\section{Conclusions}

This somewhat lengthy review and discussion of the phylogeny of the sternum in the different classes of vertebrates, together with the accompanying figures, which have been adapted and modified from various sources, has revealed very clearly several facts of outstanding importance in relation to the problem of sternal origin:

1. That there is present a median ventral rudiment, derived from the coracoids, which may be identified as a presternum as far back in the vertebrate series as the shark, and can be followed up through a ganoid, a teleost, a dipnoan, and from there on through the Tetrapoda.

2. That in all cases of vertebrates, and as high as man in the Mammalia, there is in the embryo or throughout life a continuous girdle across the ventral side and connecting the two scapulae above.

3. That this girdle in its ventral aspect is in the most intimate relation to the anterior part of the sternum; sometimes the mesenchymatous material passes over insensibly from one structure into the other without any line of demarkation; or at most, adults of Amphibia and Reptilia, there being but a suture between the two parts.

4. That in all these forms from the lowest to the highest, the relation of sternum and ribs is purely secondary and the result of a comparatively late fusion of the two structures in the embryo. The presence or absence of ribs does not seem to affect the development or size of the sternum in any degree.

5. That plural ribs extending to the ventral side of the body are a recent acquisition of the vertebrates, while the shouldergirdle and sternum are coexistent and intimately related from the earliest appearance of the Gnathosomes. 
6. That the number of ribs reaching the sternum varies from zero to a large number; sometimes the ribs are attached to the anterior part of the sternum, again exclusively to the posterior part, but apparently whatever the number or relation of ribs, the sternum remains unaffected, indicating strongly its independence of the costal cartilage.

7. That the evidence presented seems to bear out the homology of the sterna throughout the vertebrates; therefore, to classify them as coracoidal for the lower groups, and costal for the higher is unnecessary and artificial, for in the Amniota the sternum is as truly coracoidal in origin as it is in the Ichthyopsida.

8. That the mesosternum and xiphisternum are two backward prolongations of the coracoidal presternum, sometimes uniting in the midline (some reptiles, birds, and mammals), again remaining distinct as horns or bars (some Amphibia, some reptiles).

\section{SUMMARY}

At the close of the section on the ontogeny of the sternum a number of conclusions were listed, and likewise at the close of the section on phylogeny. These results may now be gathered up in the three main theses of this paper, which are stated thus:

1. That the sternum is an homologous structure throughout all groups of vertebrates, and occurs in forms ranging from Hexanchus up to the highest mammals.

2. That the anterior element of the sternum has its origin in common with the shoulder-girdle, and in the embryo or throughout life is in intimate relation to the coracoids.

3. That the sternal bands are derivatives of the anterior median rudiment, and may be secondarily, but never genetically, associated with ribs. 


\section{LITERATURE CITED}

Adolphi, H. 1905 Über die Variation des Brustknorbes und der Wirbelsäule des Menschen. Morph. Jahrb., Bd. 33.

Anthony, R. 1901 Notes sur la Morphogenie du sternum chez Mammiferes a propos de l'etude de Paterson sur le developpement de cet os. Bull. Soc. Anthrop. Paris (5), T. 2, pp. 19-43.

Broom, R. 1897 On the existence of a sternocorocoidal articulation in a fetal marsupial. Jour. of Anat. and Physiol., vol. 31.

1898 Description of the shoulder-girdle in an $8.5-\mathrm{mm}$. embryo of trichosurus (not exact title). Proc. Linn. Soc. N. S. W., 1898.

1899 On the development and morphology of the marsupial shouldergirdle. Trans. Roy. Soc. Edinb., vol. 39, pt. 3, pp. 749-770.

1902 On the early condition of the shoulder-girdle in the Polyprotodont Marsupials Dasyurus and Permales. Linn. Soc. Jour. Zool., vol. 28.

1908 On the nomenclature of the elements of the amphibian shouldergirdle. Report S. Afr. Assoc. Adv. Sc., 6th. Meet., pp. 162-166.

Bruch, CarL 1852 Beiträge zur Entwicklungeschichte des Knochensystems von Dr. Carl Bruch. Neue Denkschriften der allgemeinen Schweizerischen Gesellschaft für die gesammten Naturwissenschaften. Bd. 12, Zurich (quoted by Ruge).

Credner 1881-1893 Stegocephalen und Saurier. Zeitschr. deutsch. Geolog. Gesellsch., 1881-1893.

Cunningham, D. J. 1890 The occasional eighth, true rib in man and its relation to right-handedness. Jour. Anat. and Physiol., vol. 24, p. 127.

Dwight, Thomas 1890 Irregular union of the first and second pieces of the sternum in man and the apes. Jour. Anat. and Physiol., vol. 24, pp. $536-542$.

GoËтTE, A. 1877 Morphologie des Skelettsystems der Wirbeltiere: Brustbein und Schultergürtel. Arch. f. Mikr. Anat., Bd. 14.

Goodrich 1909 Vertebrate Craniata (first fasicle): Cyclostomes and fishes. A treatise on zoology, pt. 9, by E. Ray Lankester. London.

Gregory, W. K. 1915 Present status of the problem of the origin of the Tetrapoda. Ann. N. Y. Acad. Sc., vol. 26.

Gunther 1867 Anatomy of Hatteria (Sphenodon). Phil. Trans., 1867.

Haswell, W. A. 1884 Studies on the elasmobranch skeleton. Proc. Linn. Soc. N. S. W., vol. 9.

Hoffmann, C. K. 1879 Zur Morphologie des Schultergürtels und des Brustbeins bei Reptilien, Vögeln, Säugetieren, und dem Menschen. Niederland. Archiv. f. Zool., Bd. 5.

Howes, G. B. 1891 Morphology of the sternum. Nature, vol. 43.

Howes and Swinnerton 1901 Development of the skeleton of Sphenodon. Trans. Zool. Soc. Lon., vol. 16.

Hontington, G. S. 1918 Modern problems of evolution, variation, and inheritance in the anatomical part of the medical curriculum. Anat. Rec., vol. 14, no. 6.

Keibel and Mall 1910-1912 A manual of human embryology. J. B. Lippincott Co., Phila. 
Kingsley, J. S. 1917 Comparative anatomy of vertebrates. 2nd ed. P. Blakiston's Sons \& Co., Phila.

Kirchner, A. 1898 Das obere Brustbeinende und das ligamentum interclaviculare nebst zusammenstellungen über das Verhältnis des oberen sagittalen Brustdurchmessers und der Brustbeinlänge zur Körperlänge. Anat. Hefte., Bd. 10, S. 127-149.

Kravetz, L. P. 1905 Entwicklungsgeschichte des Sternum und des Episternalapparatus der Säugetiere. Bull. Soc. Imper. Natur. Moscow, 1905, 1906.

LiCkLey, J. D. 1904 On the relations of the seventh and eighth ribs to the sternum. Anat. Anz., Bd. 24.

Markowski, J. 1905 Sollte der Verknöcherungsprozess des Brustbeins von keiner morphologischen Bedeutung sein? Aus anlass einer Publikation von Paterson. Anat. Anz., Bd. 26, S. 248-269.

Mueller, Charlotte 1906 Zur Entwicklung des menschlichen Brustkorbes. Morph. Jahrb., Bd. 35.

PARKer, W. J. 1868 Structure and development of the shoulder-girdle and sternum in the vertebrates. Ray Soc. Pub., London.

PARker, T. J. 1891 On the presence of a sternum in Notidanus indicus. Nature, vol. 43, p. 142.

1891 On the origin of the sternum. Trans. New Zealand Instit., vol. 23.

Paterson, A. M. 1900 The sternum; its early development and ossification in man and mammals. Jour. Anat. and Physiol., vol. 35, N. S., vol. 15 , pt. 1.

1902 Development of the sternum and shoulder-girdle in mammals. Brit. Med. Jour., vol. 2.

1904 The human sternum. Liverpool.

1909 Two abnormal sterna in living subjects. Jour. Anat. and Physiol., vol. 43, pp. 322-323.

Rathke, H. 1838 Sur le devellopment du sternum. Arch. Anat. et Physiol.

1848 Über die Entwicklung der Schildkröten. Brunswick.

1853 Über den Bau und die Entwicklung des Brustbeins der Säurier. Königsberg.

Ruge, G. 1879 Über die Entwickelung des Sternum. Morph. Jahrb., Bd. 5. 1880 Untersuchungen über Entwickelungsvorgänge am Brustbein und der Sterno-clavicularverbindung des Menschen. Morph. Jahrb., Bd. 6.

Sabatier, A. 1897 Morphologie du sternum et des clavicules. C. R. Acad. Sc. Paris, T. 124 , no. 15.

1902 Du systeme sternal des vertebres. C. R. Ass. Anat., 4me, pp. 99-102.

SChadinsland 1900 Entwicklungsgeschichte der Hatteria (Sphenodon). Arch. f. Mikr. Anat., Bd. 56.

Seeley, H. G. 1892 Researches on the structure, organization and classification of the fossil Reptilia. Phil. Trans., vol. 183-B, pp. 334-338. 1894 Researches on the structure, organization, and classification of the fossil Reptilia. Phil. Trans., vol. 185-B. 
TREDGold 1897 Variations of ribs in the Primates, with especial reference to the number of ribs in man. Jour. Anat. and Physiol., vol. 31.

Watson, D. M. S. 1917 The evolution of the tetrapod shoulder-girdle and forelimb. Jour. of Anat., vol. 52, pt. 1.

Whitehead and Waddell 1911 Development of the human sternum. Am. Jour. Anat., vol. 12, pp. 89-106.

Wilder, H. H. 1903 The skeletal system of Necturus maculatus Rafinesque. Mem. Bost. Soc. Nat. Hist., vol. 5, no. 9.

Williston, S. W. 1903 North American Plesiosaurs. Field Col. Mus. Pub. 73. Geol. Ser., vol. 2, no. 1.

1903 On the osteology of Nyctasaurus (Nyctodactylus). Field Col. Mus. Pub. 78. Geol. Ser., vo.. 2, no. 3.

1911 American Permian vertebrates. Chicago.

1914 Water reptiles of the past and present. Chicago.

Woodward 1898 Vertebrate paleontology. Cambridge. 


\section{PLATE 1}

\section{EXPLANATION OF FIGURES}

1 Median portion of pectoral girdle of Hexanchus. Note the medial 'intercepted cartilage' which bears all the relations of a presternum in higher forms. The dotted lines indicate how this girdle may be transformed into that of the Amphibia with pre- and post-omosternum. Drawing from a dissection made by the author in the U. S. National Museum.

2 Pectoral girdle of Acanthias vulgaris. Note that all the parts of the girdle of higher forms are present, including a sternum. Compare with figure 35 of the fetal marsupial.

$\mathrm{Cr}$, coracoid

POSt, pre-omosternum

$P S t$, presternum

Sc, scapula

PtOSt, post-omosternum

$S S c$, suprascapula

$S t$, sternum 
FRANK BLAIR HANSON
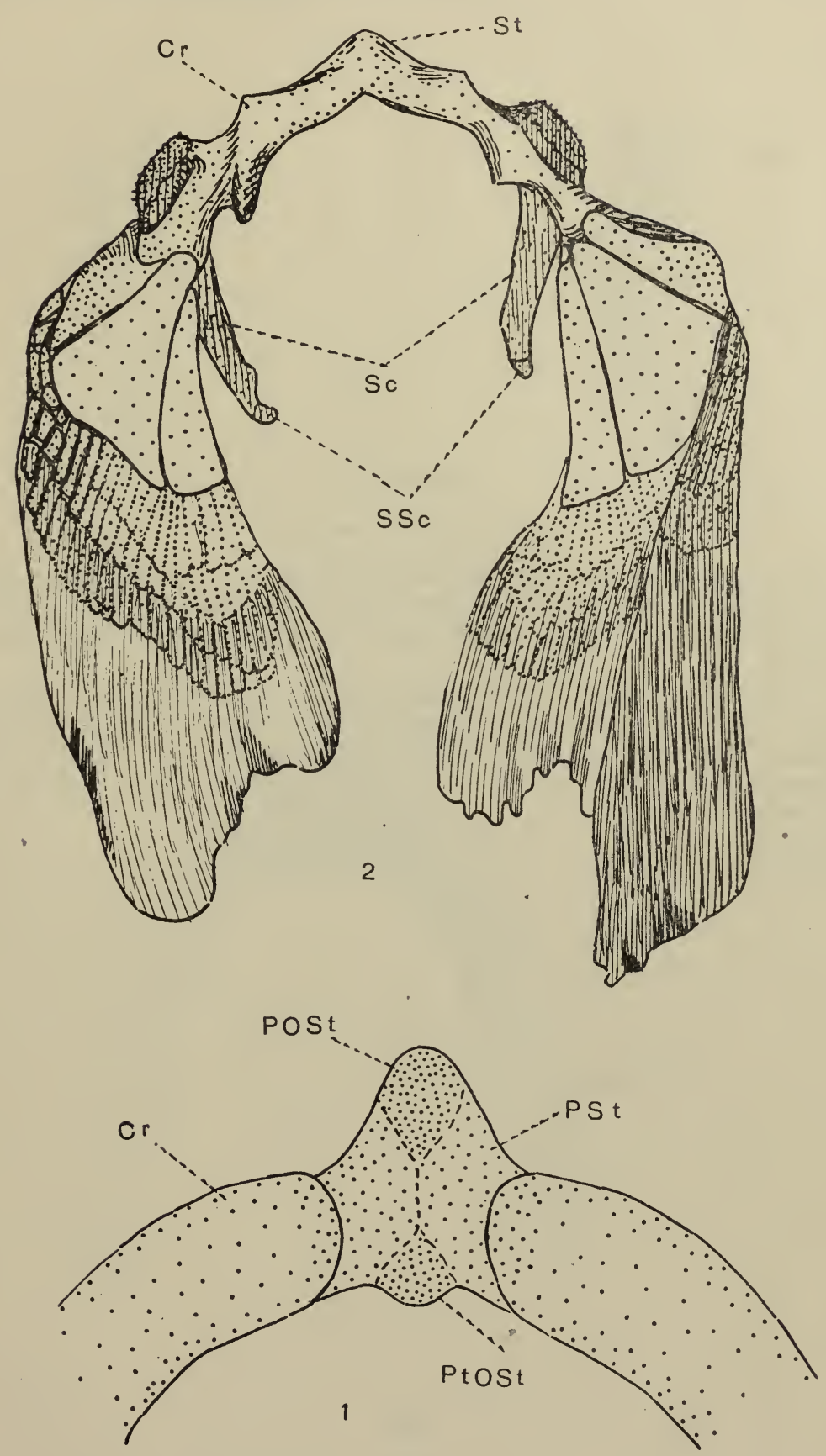


\section{PLATE 2}

EXPLANATION OF FIGURES

3 Cat embryo, $12 \mathrm{~mm}$. Sternal bands are far apart. No presternum present at this stage. The first three pairs of ribs fail to reach the sternal bands. From the Princeton Embryological Collection, series no. 401. Graphic reconstruction.

4 Cat embryo, $14 \mathrm{~mm}$. Sternal bands nearer to each other. Presternum has arisen and connects the anterior ends of sternal bands. All ribs reach the sternum. From the Princeton Embryological Collection, no. 37. Graphic reconstruction.

$P S t$, presternum

$R^{1}$, first rib

$R,{ }^{4}$ fourth rib

$R^{3}$, third rib

$R,{ }^{7}$ seventh rib

$S t B$, sternal bands 

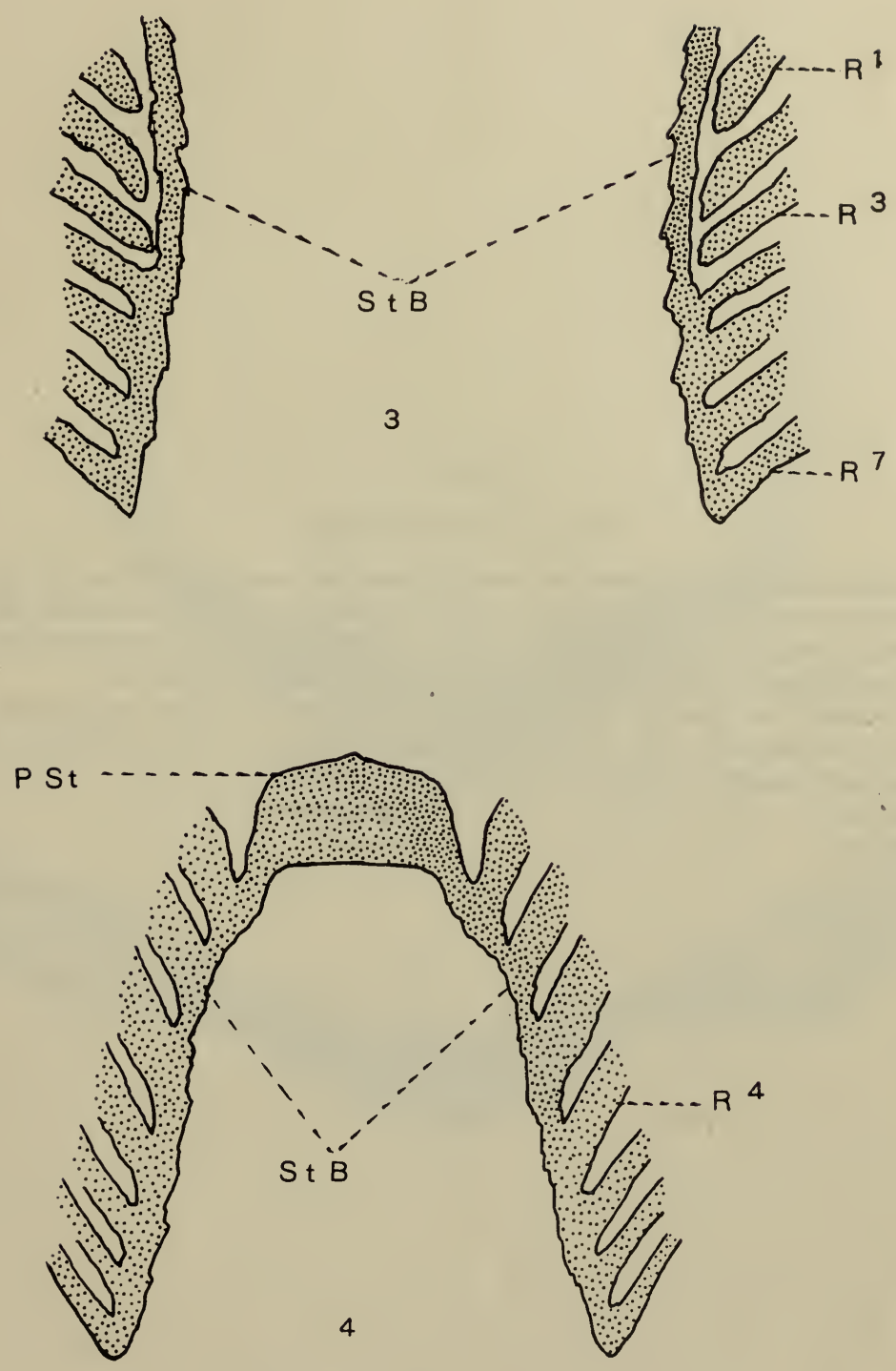


\section{PLATE 3}

\section{EXPLANATION OF FIGURES}

5 Mouse girdle. Scapulae, coracoids, clavicles, and presternum, all in one continuous mesenchymatous girdle, which is similar to that of the dogfish (fig. 1) and the marsupial fetus (fig. 35). From the Washington University School of Medicine Embryological Collection, series no. 102, slide 4, section 16.

6 Human embryo girdle. Mesenchymatous stage. First appearance of clavicle; presternum and coracoids present. From The Johns Hopkins Em. bryological Collection, series no. 424, slide 5, section 16 .

$\mathrm{Cl}$, claviicle

$\mathrm{Cr}$, coracoid

$P S t$, presternum

$S c$, scapula 
FRANK BLAIR HANSON
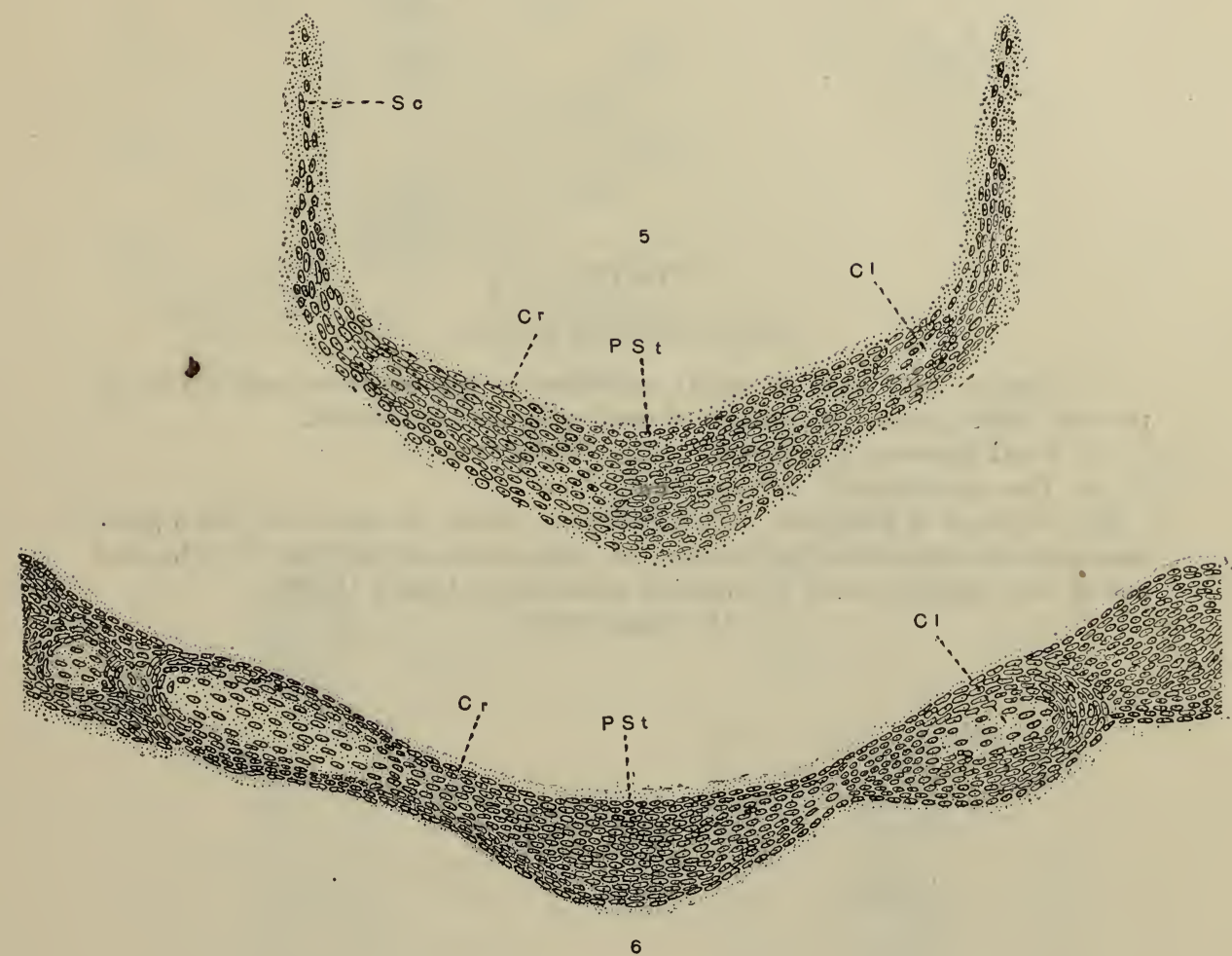


\section{PLATE 4}

EXPLANATION OF FIGURES

7 Sternum and ends of costal cartilages in pig two weeks old. Note in this and later figures that centers of ossification are intercostal.

8 Fetal sternum of Bradypus. After Hoffmann.

9 The ape sternum. After Anthony.

10 Sternum of Dasypus. After Hoffman. From the lowest to the highest mammals the sternebrae and centers of ossification are between the ribs, and not at their ends as would be expected according to Ruge's theory.

Oc, ossific center 


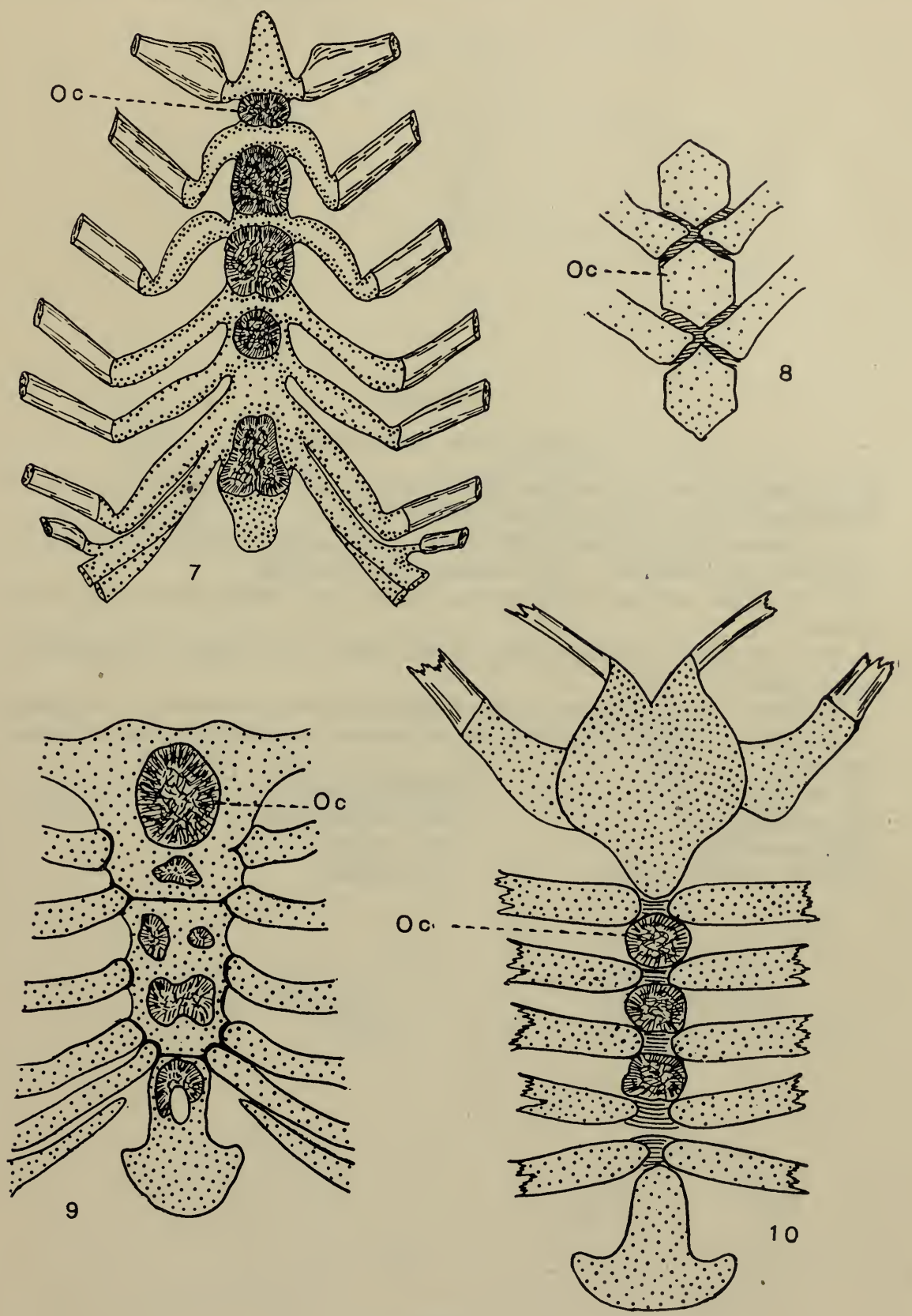


PLATE 5

\section{EXPLANATION OF FIGURES}

11 Ventral portion of shoulder-girdle of the shark, Notidanus indicus, showing the presternum in the midline. After Parker.

12 Ventral part of the shoulder-girdle of Polypterus. Note epicoracoid at junction of the clavicles. From Gregory, after Goodrich.

13 Clavicles and epicoracoid of the tropical fish, Gobius niger Linn., after Parker.

14 to 15 . Upper and lower views of the girdle of the Dipnoid, lepidosiren. After Parker.

16 to 19 A series of stages in the development of the sternum of the frog, Rana temporaria, indicating that the sternum is coracoidal in origin. After Parker.

$\mathrm{Cl}$, clavicle

PtOmSt, post-omosternum

$\mathrm{Cr}$, coracoid OSt, omosternum

$E C r$, epicoracoid

Sc, scapula

PrOmSt, pre-omosternum

St, sternum 


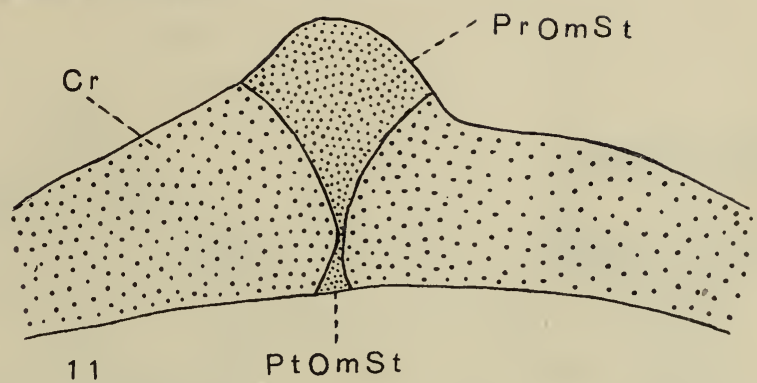

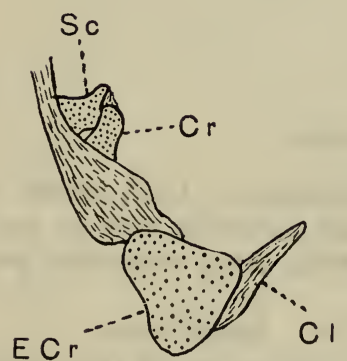

12
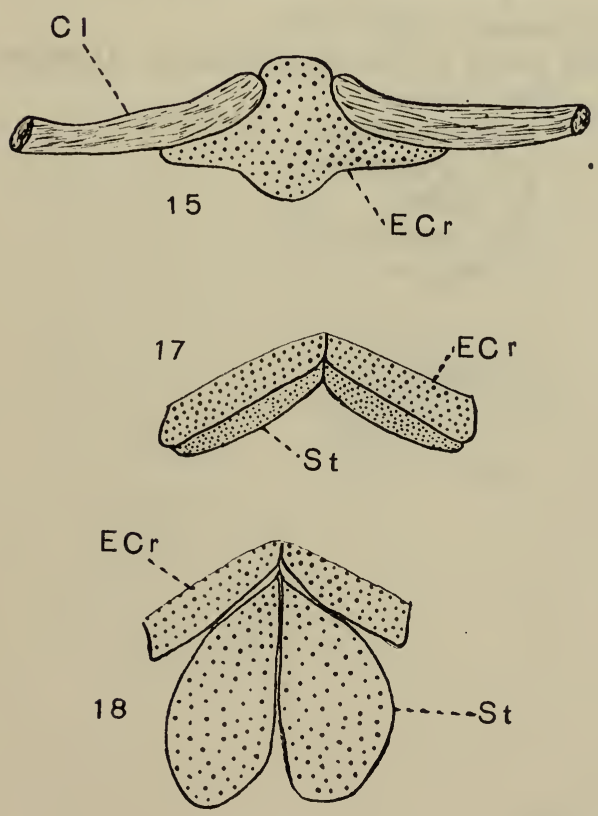

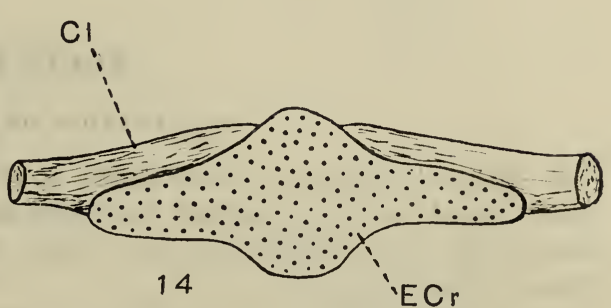

13
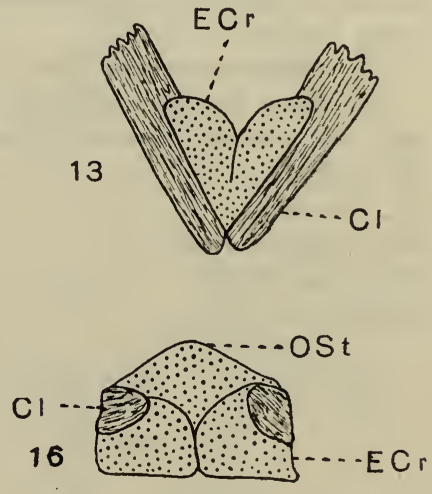

ECr

19

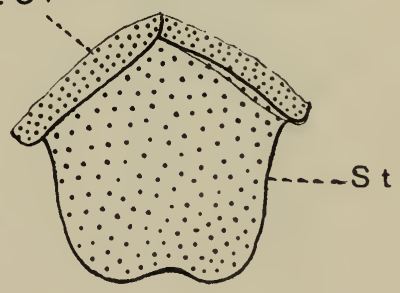




\section{PLATE 6}

\section{EXPLANATION OF FIGURES}

20 Shield-like plate on ventral side of Pipa dorsigera. Adult female, upper view. Would seem to indicate that sternum and coracoids were at one time structurally one; omosternum but feebly separated from coracoidal portion. After Parker.

21 Bufo vulgaris. First summer. Lower view. After Parker.

22 Large specimen of Siredon pisciformis. Sternum cut off from coracoids in adult, but retain evidences of having come from the overlapping epicoracoids. After Parker.

23 Dactylethra capensis. Adult female. After Parker.

24 . Note the beginning of sternal bands in Calamites cyaneus. Compare with same stage in low-type reptile. After Parker.

$C l$, clavicle

$\mathrm{Cr}$, coracoid

Crf, coracoid fossa

$E C r$, epicoracoid

$G l$, glenoid
$O S t$, omosternum

$P C r$, precoracoid

Sc, scapula

$S S c$, suprascapula

St, sternum 

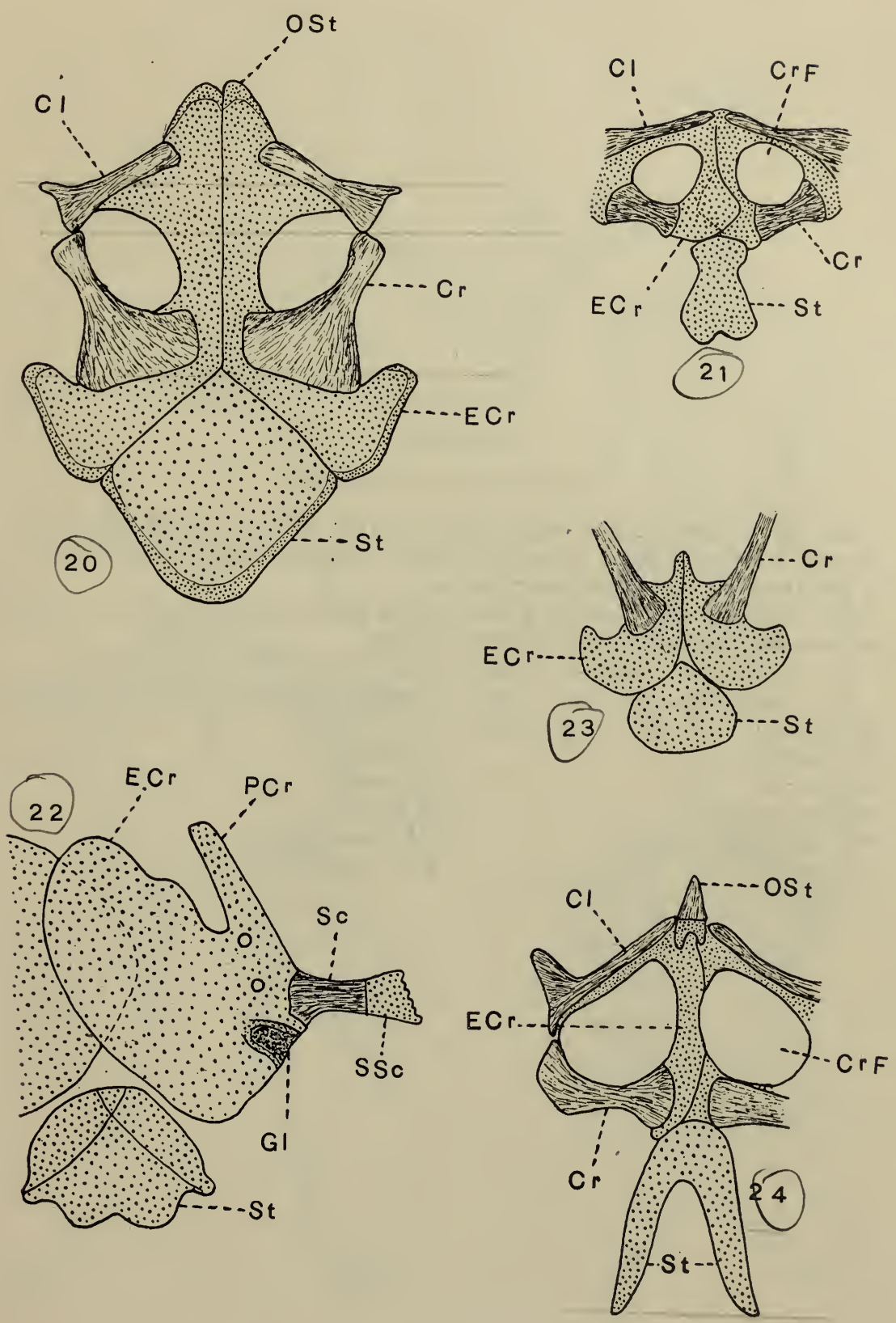


\section{PLATE 7}

\section{EXPLANATION OF FIGURES}

25 An old specimen of Anguis fragilis. Very similar to amphibian girdle. No ribs attached. Same intimate relation of sternum and coracoidal part as in the Amphibia. Modified after Parker.

26 In Stellio cordylinus long sternal bars make their appearance. No ribs are attached to them. Adapted from Parker.

27 Laemanctus longipes. After Parker.

28 Trachydosaurus rigosus adult. Sternal bars are fused and ribs are approaching. Adapted from Parker.

$E C r$, epicoracoid

$G l$, glenoid

$I C l$, interclavicle

$P C r$, precoracoid

$P S t$, presternum
$R^{1}$, first rib

Sc, scapula

$S t$, sternum

$S t f$, sternal fossa

$X S t$, xiphisternum 


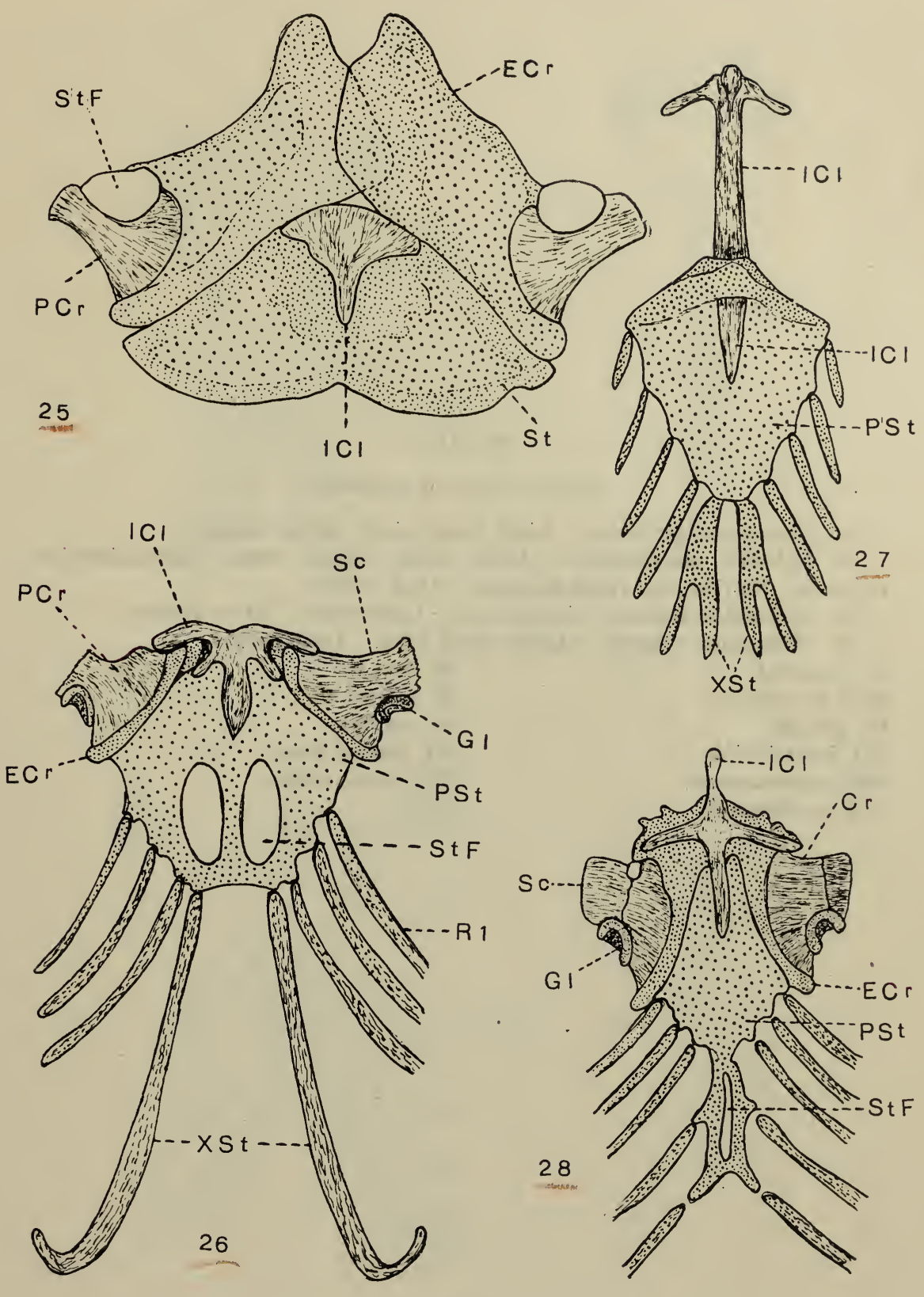




\section{PLATE 8}

\section{EXPLANATION OF FIGURES}

29 Cyclodus nigroluteus. Adult, lower view. After Parker.

30 Chirotes canaliculates. Adult male. Upper view. Mammalian-like sternum. No ribs ever reach sternum. After Parker.

31 Crocodilus acutus. Ripe embryo. Lower view. After Parker.

32 Chamaeleo vulgaris. Adult, lower view. After Parker.

$C r$, coracoid

$E C r$, epicoracoid

$G l$, glenoid

$I C l$, interclavicle

MSt, mesosternum

$P S t$, presternum
$R^{1}$, first rib

$R^{2}$, second rib

Sc, scapula

Stf, sternal fossa

$X S t$, xiphisternum 

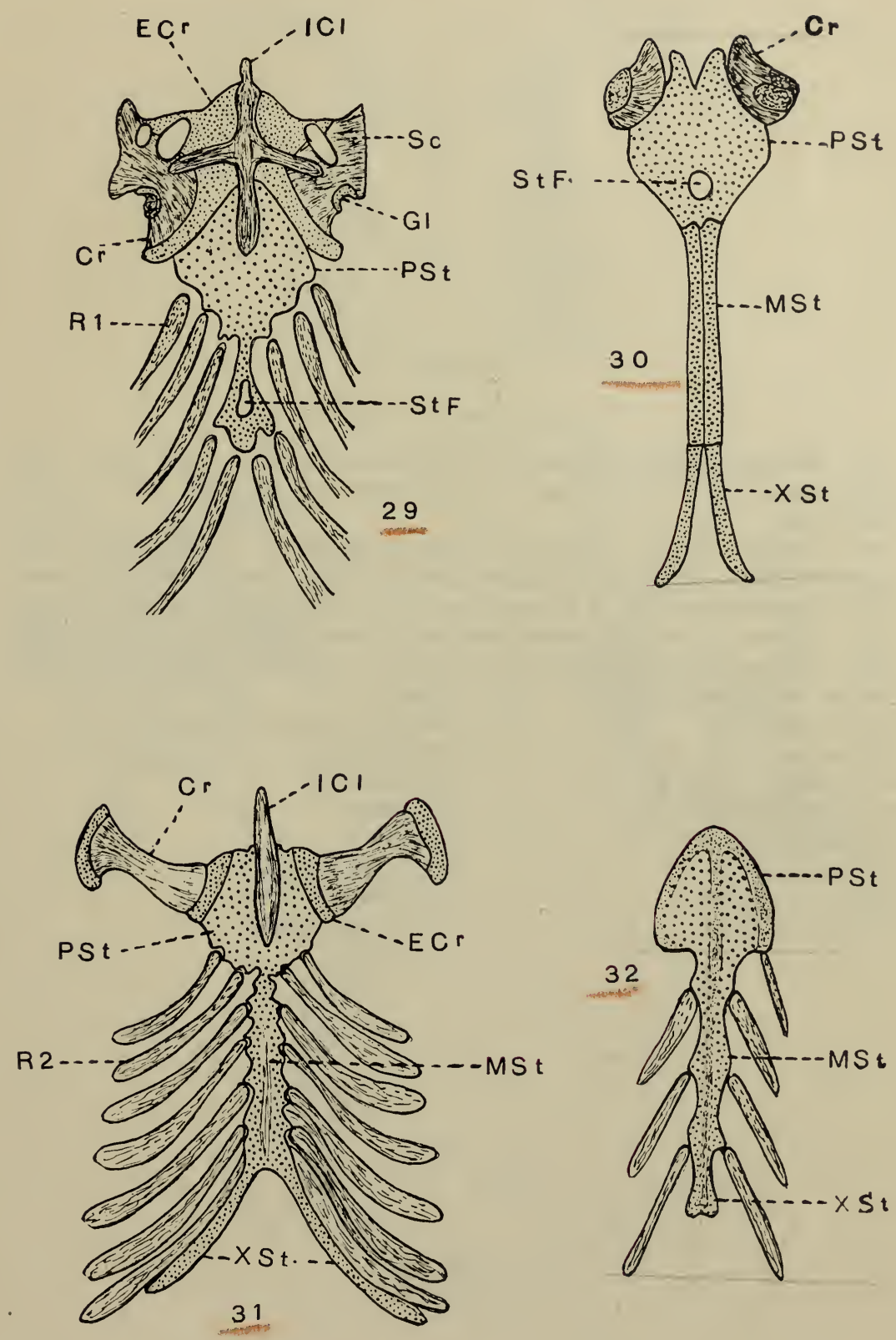


\section{PLATE 9}

\section{EXPLANATION OF FIGURES}

33 Vanellus custatus. One-third of incubation period. Lower view. Note slight attachment of ribs, but only sutural separation of sternum and coracoid. After Parker.

34 Echnidna histrix. Upper view of adult specimen. Drawn from a specimen in Washington University, Department of Zoology, and in part after Parker.

35 Shoulder-girdle of a marsupial embryo, Trichosurus. Scapulae, coracoids, and sternum are continuous parts as in the shark embryo. After Broom.

36 Anterior view of girdle in an $8.5-\mathrm{mm}$. Trichosurus embryo. Dotted portions are mesenchymatous. After Broom.

$A c$, acromian

$\mathrm{Cl}$, clavicle

$\mathrm{Cr}$, coracoid

$E C r$, epicoracoid

$G l$, glenoid

$I C l$, interclavicle

$\mathrm{OSt}$, omosternum

$\mathrm{PCr}$, precoracoid
Pro, pre-omosternum

$R^{1}$, first rib

$R^{2}$, second rib

Sc, scapula

$S p$, spine

$S S c$, suprascapula

St, sternum

$X S t$, xiphisternum 
ONTOGENY AND PHYLOGENY OF THE STERNUM FRANK BLAIR HANSON
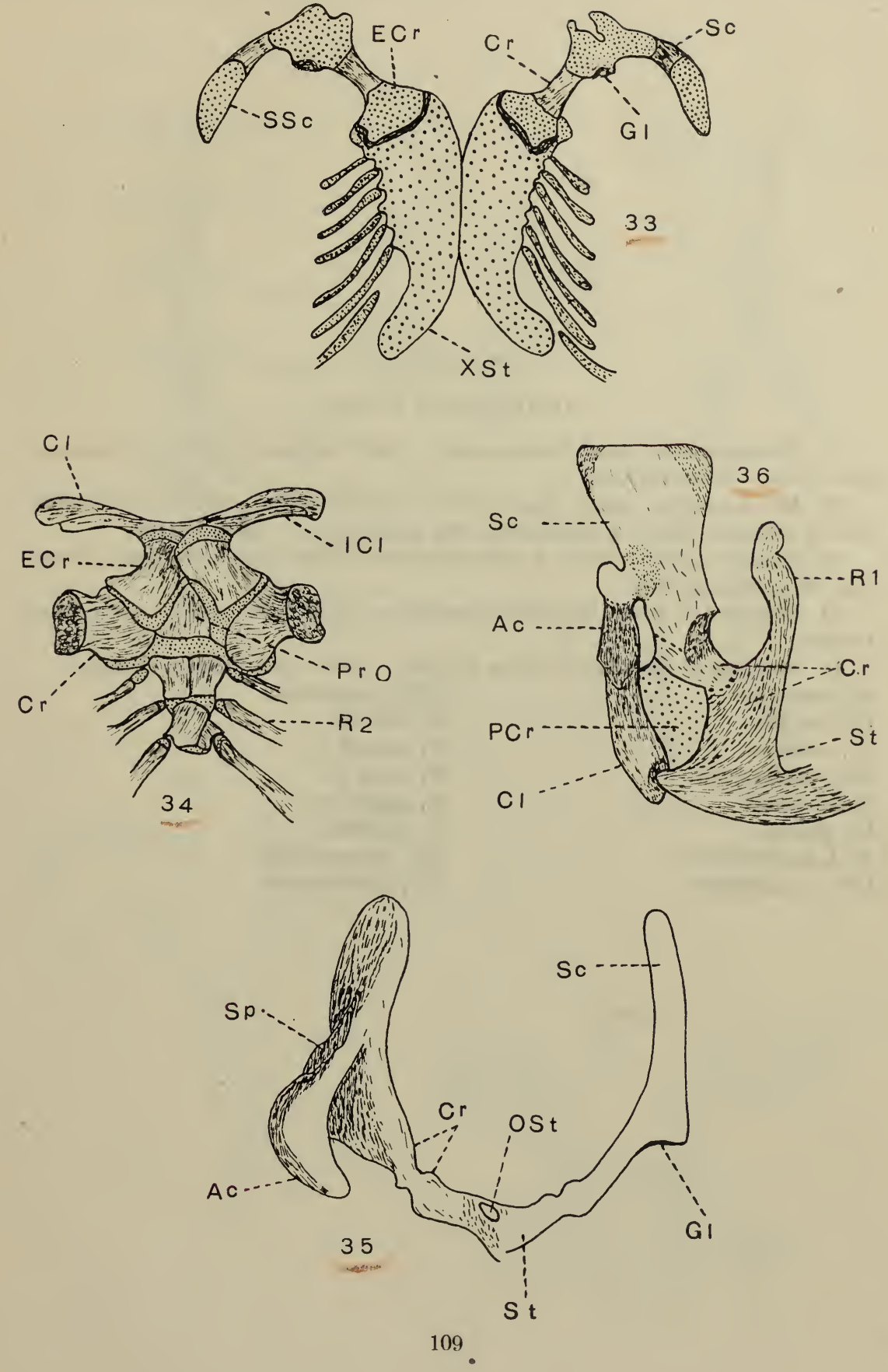


\section{PLATE 10}

\section{EXPLANATION OF FIGURES}

37 Petrogale xanthopus, 3 inches long. Right scapula, outer view; sternum, inner view. After Parker.

38 Mus musculus, adult, inner view. Anterior end of sternum and medial end of clavicles, showing omosterna, and epicoracoids. After Parker.

39 Shoulder-girdle seen in a reconstruction of Dasyurus viverrinus. Front view of mammary fetus.

40 Sternum of adult Manatus americanus. Left half, inner view. After Parker.

41 Sternum of the embryo of the Dolphin. Inner view. After Parker.

Ac, acromian

$C l$, clavicle

$\mathrm{Cr}$, coracoid

$E C r$, epicoracoid

$F$, fontanelle

$G l$, glenoid

$M S t$, mesosternum

OSt, omosternum
$P S T$, presternum

$R^{1}$, first rib

$R^{2}$, second rib

$R^{3}$, third rib

$R^{8}$, eighth rib

Sc, scapula

$S S c$, suprascapula

$X S t$, xiphisternum 


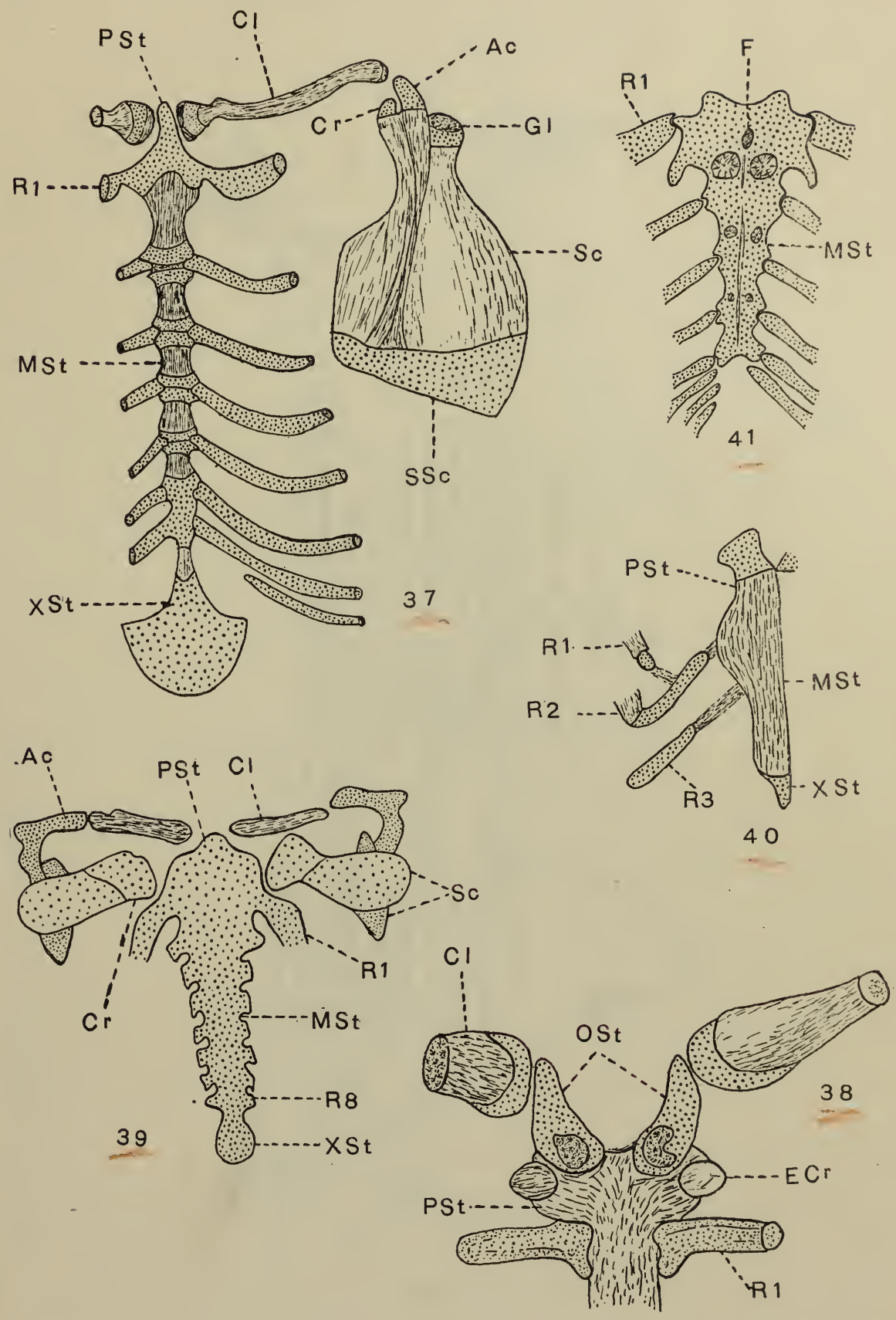

THE AMERICAN JOURNAL OF ANATOMY, VOL. 26 , NO. 1 


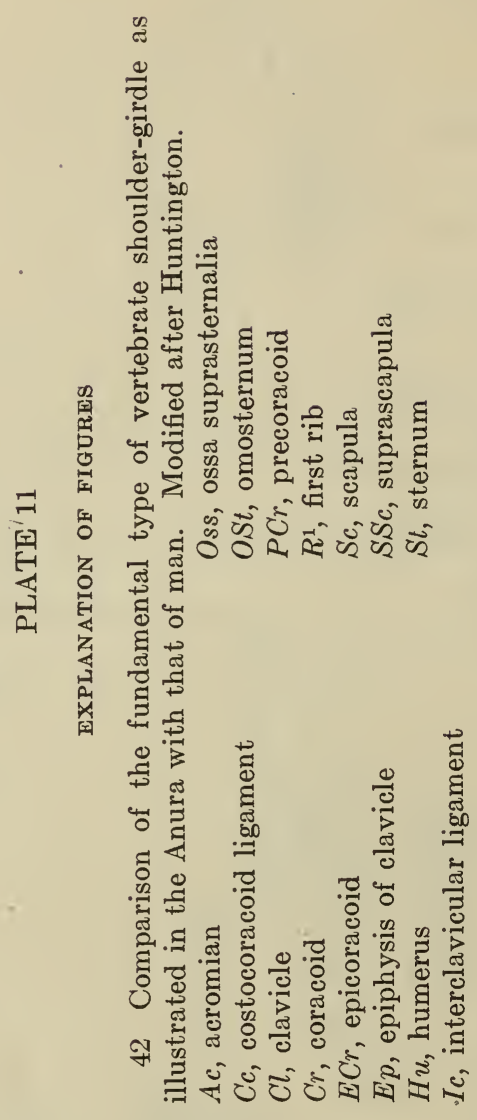


䍃

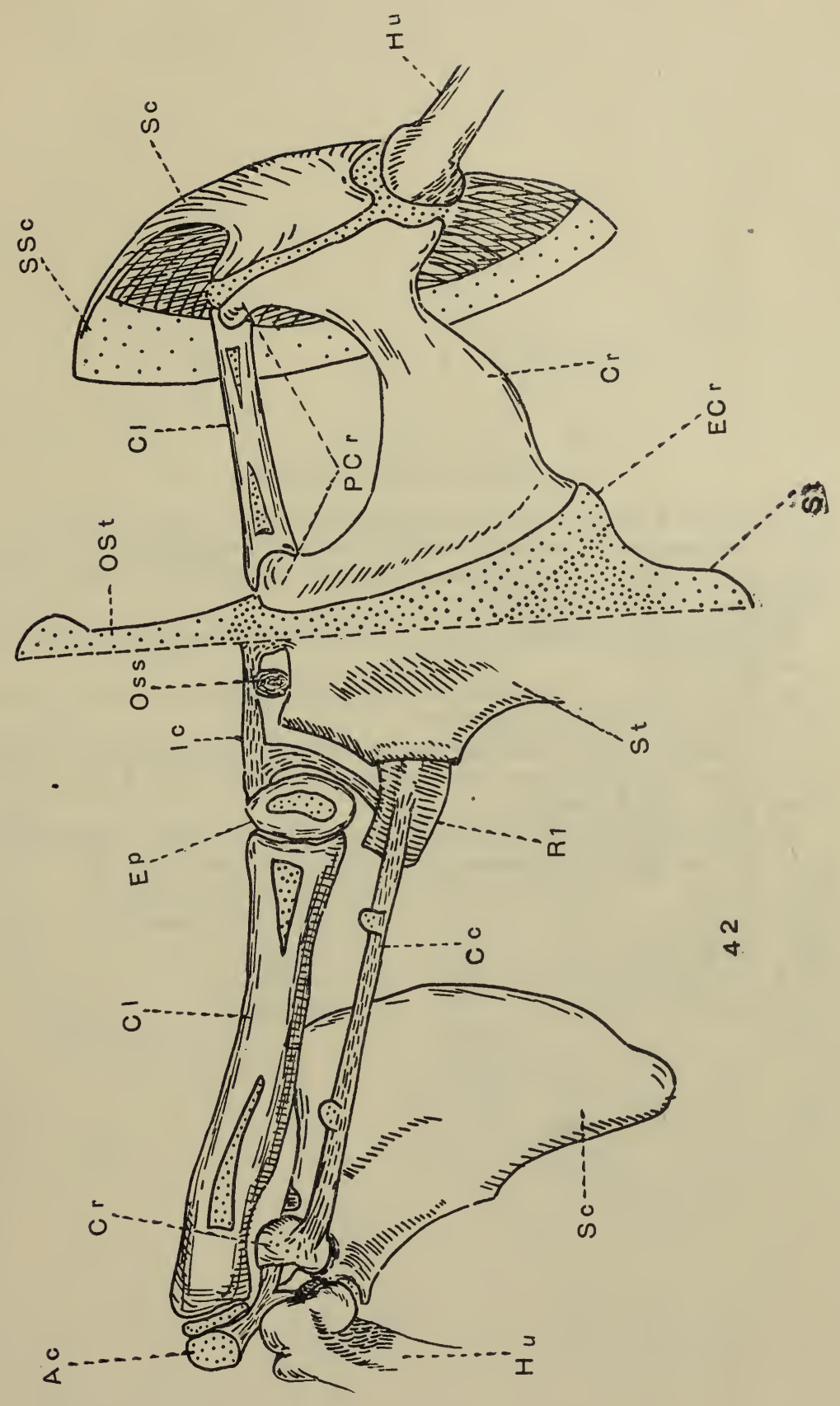




\section{PLATE 12}

EXPIANATION OF FIGURES

43 Girdle of Hexanchus. Pre- and post-omosterna. After Parker.

44 Diagrammatic transverse section through shoulder-girdle of adult frog.

45 Section through edges of shoulder-girdle and sternum of adult Lissotriton punctatus. After Parker.

46 Diagrammatic transverse section of arch in the Australian lizard, Trachydosaurus rugosus.

47 Diagrammatic transverse section of Echnidna histrix, from a mounted specimen in Washington University.

48 Anterior view of cartilaginous girdle of petrogale, $21 \mathrm{~mm}$. in length. The different parts of the girdle are outlined, but the whole is a continuous piece of cartilage. After Broom.

49 Transverse section of mouse embryo, $7.75 \mathrm{~mm}$. long. Washington University School of Medicine series no. 102, slide 4, section 16 . $\times 38$.

Ac, acromian

$\mathrm{Cr}$, coracoid

$E C r$, epicoracoid

$G l$, glenoid

$H u$, humerus
$\mathrm{PrOmSt}$, pre-omosternum

$\mathrm{PtOmSt}$, post-omosternum

$S c$, scapula

SSc, suprascapula

$S t$, sternum 
FRANK BLAIR HANSON
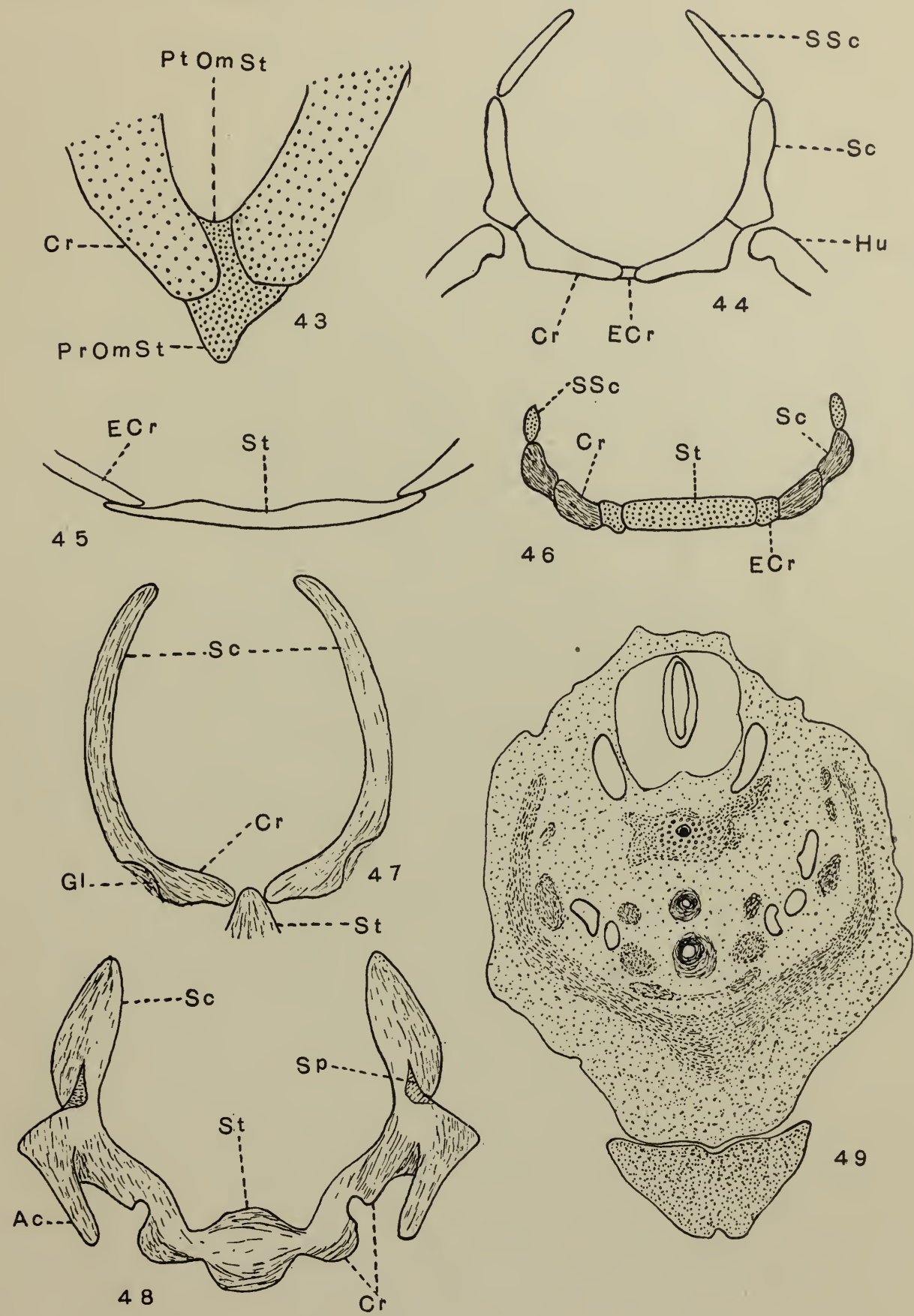




\section{THE AMERICAN JOURNAL OF ANATOMY}

VOLUME 26, NUMBER 1, SEPTEMBER 15, 1919

\section{CONTENTS}

H. E. Jordan. The histology of the umbilical cord of the pig, with special reference to the rasculogenic and hemopoietic activity of its extensively vascularized connective tissue. Fifteen figures.

Henry A. Murray, Jr. The development of the cardiac loop in the rabbit, with especial reference to the bulboventricular groove and origin of the interventricular septum. Seven figures.

Frank Blair Hanson. The ontogeny and phylogeny of the sternum. Twelve plates

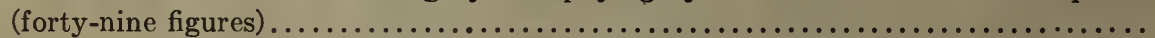

George W. Corner. On the origin of the corpus luteum of the sow from both granulosa and theca interna. Twenty-six figures................................. 117 